\title{
INVESTIGATING ABNORMAL VOLATILITY TRANSMISSION PATTERNS BETWEEN EMERGING AND DEVELOPED STOCK MARKETS: A CASE STUDY
}

\author{
Cristi SPULBAR ${ }^{1}$, Jatin TRIVEDI ${ }^{2}$, Ramona BIRAU ${ }^{3 *}$ \\ ${ }^{1}$ Faculty of Economics and Business Administration, University of Craiova, Craiova, Romania \\ ${ }^{2}$ National Institute of Securities Markets, Maharashtra, India \\ ${ }^{3}$ Faculty of Education Science, Law and Public Administration, \\ Constantin Brancusi University of Targu Jiu, Targu Jiu, Romania
}

Received 04 January 2020; accepted 16 June 2020

\begin{abstract}
The main aim of this paper is to investigate volatility spillover effects, the impact of past volatility on present market movements, the reaction to positive and negative news, among selected financial markets. The sample stock markets are geographically dispersed on different continents, respectively North America, Europe and Asia. We also investigate whether selected emerging stock markets capture the volatility patterns of developed stock markets located in the same region. The empirical analysis is focused on seven developed stock market indices, i.e. IBEX35 (Spain), DJIA (USA), FTSE100 (UK), TSX Composite (Canada), NIKKEI225 (Japan), DAX (Germany), CAC40 (France) and five emerging stock market indices, i.e. BET (Romania), WIG20 (Poland), BSE (India), SSE Composite (China) and BUX (Hungary) from January 2000 to June 2018. The econometric framework includes symmetric and asymmetric GARCH models i.e. EGARCH and GJR which are performed in order to capture asymmetric volatility clustering, interdependence, correlations, financial integration and leptokurtosis. Symmetric and asymmetric GARCH models revealed that all selected financial markets are highly volatile, including the presence of leverage effect. The stock markets in Hungary, USA, Germany, India and Canada exhibit high positive volatility after global financial crisis.
\end{abstract}

Keywords: volatility spillovers, developed stock markets, emerging stock markets, GARCH models, correlation.

JEL Classification: C58, D53, G15, O57.

\section{Introduction}

The degree of financial integration is different for developed markets compared to emerging markets, this variation being an essential aspect of the investment process. Financial liberalization is associated with the idea of achieving very attractive investment opportunities

*Corresponding author. E-mail: ramona.f.birau@gmail.com

Copyright (c) 2020 The Author(s). Published by Vilnius Tech Press

This is an Open Access article distributed under the terms of the Creative Commons Attribution License (http://creativecommons. org/licenses/by/4.0/), which permits unrestricted use, distribution, and reproduction in any medium, provided the original author and source are credited. 
in the case of developed economies considering the positive effects of economic growth. On the contrary, global financial liberalization exhibits a much lower influence on emerging economies so the positive impact is not so relevant. Financial integration process is an effective alternative for identifying investment strategies in order to optimize the risk management. Portfolio diversification represents an essential investment strategy in managing stock market risks. A well-diversified portfolio can significantly reduce investment risks and lead to higher returns. Spulbar and Birau (2019) suggested that volatility does not diverge to infinity and seems to react significantly different considering the case of high positive or high negative stock returns. Moreover, portfolio diversification strategy is a representative phenomenon of quantitative finance, most often applied in relation to low or negative correlations between financial assets, such as stock market indices. However, different stock market indices may move in opposite directions or in the same direction. Even if two stock indices move in the same direction, they may have a different magnitude, and this will mitigate the portfolio fluctuations. Positively correlated stock markets tend to move together in the same direction. Consequently, portfolio diversification and a high positive correlation represent opposite weights. Further, different stock markets consist different leverage effect and standard deviations. Chowdhury and Arefin (2017) considered that emerging markets have become more interesting for international investors than developed markets because this market is considered less integrated with the global economy. In financial market, negative shocks are more common and frequent than positive shocks. However, a research study conducted by Dutta (2014) based on application of GARCH, EGARCH and GJR models found that positive shocks are more common than negative shocks.

In literature there is no universally accepted definition of contagion, but it is perceived as an unpredictable propagation of shocks. Dornbusch et al. (2000) pointed out that contagion effect refers to the relationship among the financial assets, thus the shock of one asset can be transferred to other assets and the contagion effect is tested by correlation. Calvo and Reinhart (1996) argued that the propagation of volatility is the consequence of financial interdependence between stock markets considering that contagion may be more regional than global. Nevertheless, Bonfiglioli and Favero (2005) investigated the existence of co-movements between developed stock markets of US and Germany and argued that is necessary to make a clear distinction between interdependence and contagion. Complex phenomena such as financial market integration, liberalization and globalization have led to intensification of co-movements and contagion between international stock markets from all over the world. Emerging markets are typically much smaller, less liquid, and more volatile than well-known world financial markets (Domowitz et al., 1998). Moreover, the transmission of financial shocks between emerging markets highlights very attractive investment opportunities considering international portfolio diversification strategies. On the other hand, Chiang et al. (2007) conducted an empirical study applying a dynamic conditional-correlation model on certain Asian stock markets for the sample period 1990-2003, and although empirical findings confirm a contagion effect, correlation coefficients analysis also identified a shift in variance during the crisis period, generating uncertainties regarding the benefit of international portfolio diversification. 
Selection of countries for developed and emerging are objected to capture change in volatility magnitude and diversified transmitting pattern of movement of financial market. This may also capture different degree of risk, return and investment pattern. Dow Jones Industrial Average (DIJA) index representing US stock market is one of the most impactful and representative in North America. TSX Composite Index is the most important stock index of Canada. FTSE100 index for UK along with IBEX 35 (Spain), DAX index (Germany), and CAC 40 index (France) covered European developed stock markets. NIKKEI 225 index was selected to represent Japan which is an Asian developed stock market. The selection of developed stock markets covers 3 different continents, respectively North America, Europe and Asia. In order to observe volatility transmitting impact on emerging markets, we selected the following stock indices: BET (Romania), WIG20 (Poland) and BUX (Hungary) for European countries and BSE (India) and SSE Composite Index (China) for Asian countries.

This empirical study will explore risk, return and investment patterns, volatility magnitude and prospects for investment for selected developed stock markets from America, Europe and Asia, but also for selected European and Asian emerging stock markets. Financial time series, and thus stock market daily log returns, are characterized by certain stylized facts, such as: volatility spillovers, heteroskedastic log returns, leverage effect, heteroskedasticity of log returns, financial frictions, high diversification opportunities, nonlinearity, volatility, high-frequency, non-stationary of price levels, extreme variations in time, existence of bubbles, deterministic chaos, fat-tailed distribution (leptokurtosis), non-normal distributions, misallocation of resources (capital), asymmetry and residual risk.Moreover, this research paper is organized based on the following main research directions: a) to compare index transmitting pattern among developed economies and emerging economies; $b$ ) to measure the magnitude of volatility among developed and emerging economies; and c) to rate and rank economies in terms of risk appetite/risk tolerance and stock price reaction to news and no-news on selected economies. In order to ascertain objective and produce detail first all series returns converted into log and first log difference considered for all statistical outcomes. Moreover, the phenomenon of international financial contagion is rather severe in terms of globalization.

Engle et al. (1990) suggested that "volatility appears to be a meteor shower rather than a heat wave". Almost three decades later, Chua and Tsiaplias (2019) argued that news transmission tends to crowd-in non-normal news and crowd-out normal news, considering that the effect of non-normal news on volatility expectations very often are clustering before dispersing, while larger shocks have a less persistent impact on expected volatility than normal shocks. These recent conclusions of empirical studies contradict the generic classical theory which argues that volatility of an asset's return is related to the flow of information about the asset (Ross, 1989). Spillovers represent changes in return or volatility in one market due to a transmission of specific information from other markets (Fleming et al., 1998). Nevertheless, Taufiq et al. (2006) argued that volatility in one market can spillover to another and tends to continue after that market closes and producing volatility in geographically distant markets opening several hours later. The linkages between mature and emerging financial markets have multiple implications on the investment process, but even more during financial crisis. It is an empirically confirmed fact that there is a high degree of co-movement 
between international stock markets during periods of financial turmoil. The magnitude of their dynamics differs, especially in the case of emerging stock markets. The effectiveness of international portfolio diversification is very important especially in the context of financial crises (negative shocks).

Our research questions briefly describe what our empirical study aims to accomplish. Which is the dimension of stock prices fall during extreme events such as financial crises? Is there empirical evidence of volatility spillovers and contagion between emerging and developed stock markets? What are the implications of international transmission of shocks occurred in mature stock markets for emerging stock markets? What is the magnitude of volatility spillovers from mature to emerging stock markets, and vice versa? Is the volatility spillover effect stable over time? Why volatility is much different in emerging markets compared to developed markets? How volatility spillover effect explains the benefits of international portfolio diversification? What are the implications of volatility spillovers and contagion for investors, policy makers and regulators? One of the important questions in studies of asset returns and volatility has been how long the effects of shocks persist, especially in the case of emerging stock markets Furthermore, Engle (2001) argued that the main objective of volatility analysis must ultimately be to explain the causes of volatility.

The structure of this empirical study is the following: the first section provides a literature review. Further, the second section disseminates the methodological aspects and statistical data. Section 3 includes the empirical findings and discussion. Ultimately, the last section presents the conclusions including limitations and future research directions.

\section{Literature review}

The literature review provides insight into previous empirical studies for our proposed empirical research. Bekaert et al. (2005) defines contagion as "excess correlation" or a level of correlation over what is expected considering that increased correlation is expected if the volatility of a factor increases. Forbes and Rigobon (2002) stated that contagion of return volatilities represents a significant increase in cross-market correlations after the shock. Tran (2018) suggested that contagion occurs when there is a significant increase in correlations during the turmoil period compared with those during the tranquil period. Baur (2003) emphasized that contagion tests using correlation coefficient assume constant correlations and symmetric impacts of shocks but such tests can be misleading when correlations are time-varying and volatility is contagious per se. Sentana (2018) provided a complex theoretical framework regarding the concepts of volatility, diversification and contagion because financial investors are interested in having at their disposal accurate and timely measures of risk on which to base their decisions.

Lin (2018) conducted an empirical study on modelling and forecasting the stock market volatility of SSE Composite Index using $\operatorname{GARCH}$ models, i.e. $\operatorname{GARCH}(1,1), \operatorname{TARCH}(1,1)$, and $\operatorname{EGARCH}(1,1)$ and concluded that $\operatorname{EGARCH}(1,1)$ broadly outperforms the other models used in econometric analysis. Alberg et al. (2008) conducted an empirical study on stock market return volatility of Israel (Asia) using GARCH, EGARCH and GJR models and found that asymmetric GARCH models improve overall estimations for measuring conditional variances. Hassan (2017) has performed an empirical analysis of developed stock markets 
indices, i.e. DJIA, FTSE 100 and DAX using GARCH model. Ahmed and Suliman (2011) have conducted an empirical research study based on GARCH models to estimate volatility in the daily returns of Khartoum Stock Exchange (KSE) in Sudan for the period January 2006 to November 2010 and empirical results suggested that asymmetric models provide better fit than the symmetric models due to the existence of leverage effect. Yu et al. (2019) investigated risk transmission, international spillovers and spillbacks between systemic middle-income countries (SMICs) and the U.S. using a VAR-DCC-MVGARCH model and the empirical findings revealed the presence of dynamic and asymmetric volatility spillovers and spillbacks during and beyond financial crisis. Aktan et al. (2010) have investigated relevant aspects regarding conditional volatility in the Baltic stock markets based on selected GARCH volatility models and concluded that a higher risk does not necessarily generate increasing returns. Chan and Feng (2008) argued that long-memory feature in volatility dynamics leads to false rejection of time varying risk premia. Moreover, Miralles-Marcelo et al. (2013) investigated performance of medium and small firms in Spanish stock market based on a mix of multivariate GARCH models and risk minimizing portfolios.

Bala and Takimoto (2017) have conducted an empirical research on stock returns volatility spillovers in the case of emerging and developed markets (DMs) using multivariateGARCH (MGARCH) models and suggested that DCC-with-skewed-t density model highlights higher diagnostics accuracy. Chitkasame and Tansuchat (2019) studied contagion effect on ASEAN stock markets by applying multivariate Markov switching DCC GARCH model and the empirical results indicated the existence of a strong contagion among selected stock markets. Moreover, Basso and Ferretti (1994) have investigated the behaviour of the Italian stock market based on an empirical analysis which involves applying GARCH models on selected financial time series. Gokcan (2000) has performed a comparative empirical analysis between linear GARCH $(1,1)$ and non-linear (EGARCH) models based on monthly stock market returns of 7 selected emerging countries and concluded that the accuracy of the results obtained by applying $\operatorname{GARCH}(1,1)$ model is higher. In addition, Herrera et al. (2015) investigated volatility dependence structure between the Mexican stock exchange and the world capital market using VARMA-GARCH model with Dynamic Conditional Correlation and identified a long-run equilibrium relationship, despite the effects of structural breaks associated to different financial crises during the sample period from 1987 to 2012.

Srinivasan (2011) conducted an empirical study on modelling and forecasting the stock market volatility of S\&P 500 index using GARCH family models and concluded that symmetric GARCH model it fits much better in forecasting the conditional variance of emerging stock market return series compared to the asymmetric GARCH model. Bonilla and Sepúlveda (2011) have investigated suitability of GARCH models for modelling conditional volatility of 13 selected emerging stock market indices and have suggested an inadequacy of Generalized Autoregressive Conditional Heteroscedasticity models in the case of spillover effects and output volatility. Vidanage et al. (2017) have conducted an empirical research study on various emerging Asian economies, i.e. India, Malaysia, Pakistan, Sri Lanka, Singapore and Thailand and have concluded that asymmetric EGARCH model provides results of increased accuracy compared to other models. 
Previous empirical studies have reached interesting conclusion in the context of extreme events such as financial crises. For instance, Choudhry (1996) applied an Autoregressive Conditional Heteroscedasticity Model $(\mathrm{ARCH})$ in order to investigate volatility and riskpremium in Argentina, Greece, India, Mexico, Thailand and Zimbabwe before and after the 1987 crash, and concluded that changes observed in the ARCH model are not uniform and depend on the individual characteristics of the dissimilar stock markets. Hung (2019) examined return and volatility spillover across stock markets between China and Southeast Asian countries (Vietnam, Thailand, Singapore and Malaysia) and concluded that for the stock return and their volatility transmissions, linkage between China and other markets seems to be remarkable during and after the global financial crisis. Bhar and Nikolova (2007) analized volatility spillovers between BRIC stock markets, and suggested that US equity market returns, have a significant influence upon the variance of returns seen across Brazil, Russia and India, while China is the only country where there exists a negative relationship between volatility spillover effects on a regional and global basis. Bonga-Bonga (2018) investigated the transmission of financial shocks between South Africa and other members of the BRICS using a multivariate VAR-DCC-GARCH model for the sample period 1996-2012 and concluded that South Africa is more affected by crises originating from China, India and Russia while these countries are least affected by crises originating from South Africa.

Jain and Sehgal (2019) examined volatility spillover using BEKK-EGARCH analysis among several developed stock markets, such as: Australia, Canada, France, Germany, Italy, Japan, UK and US from January 2003 to July 2014, covering three different sub-periods, i.e. prior to the 2007-2009 global financial crisis, during crisis, and post-crisis. The empirical results indicate no long-term volatility spillovers for France and Germany with Italy, UK and US in the post-crisis period and low economic influence of the US on the other mature markets as a result of the crisis, while the equity markets of Italy and the UK lead other markets in pre-crisis and crisis periods. In addition, Gulzar et al. (2019) examined financial cointegration and spillover effect of the global financial crisis on emerging Asian financial markets, such as: India, China, Pakistan, Malaysia, Russia and Korea for the sample period from 1 July 2005 to 30 June 2015 based on three subperiods pre-crisis, during crisis and postcrisis using a GARCH-BEKK model. The empirical results indicate an important spillover effect from the U.S. stock market upon selected stock markets of emerging economies, but also considerable A.R.C.H. and G.A.R.C.H. effects in all of the Asian stock markets during all sample time periods. Roni, Abbas, and Wang (2018) analized return and volatility spillovers effects among certain Asian emerging stock markets, i.e. Bangladesh, China, India, Malaysia, the Philippine, and South Korea from January 2002 to December 2016 divided into three sub-periods such as pre-crisis, crisis, and post crisis time intervals using GARCH model, pairwise Granger causality tests, and generalized VAR (vector auto regression) models. The empirical results indicate that selected Asian emerging stock markets interaction is lower before the global financial crisis period and volatility spillover reached the highest level in the most turbulent period of 2007-2008. Mathur et al. (2016) investigated the effects generated by the global financial crisis on the Indian Stock Market (BSE) based on GARCH models for the period 2001-2012 and the results of the empirical study suggest high volatility for the period 2007-2009. 
Slimane et al. (2013) investigated the volatility behaviour of certain European developed stock markets, i.e. France, Germany, and the UK using a VAR-EGARCH model and empirical findings showed that German market has significantly influenced both French and UK stock markets, especially during financial crisis. The authors explained these results considering that Germany played the role of a hub of financial and economic activity in Europe for the sample period, from 1 January 2004 to 31 December 2010. Dedi et al. (2016) examined volatility spillovers among stock markets in Germany, United Kingdom, China, Russia, and Turkey using MARMA, GARCH, GARCH-in-mean, and exponential GARCH (EGARCH) models. The empirical findings revealed the existence of significant co-movements of returns among the selected stock markets, while UK and the Chinese markets have the lowest volatilities.

Valls and Chuliá (2014) investigated volatility spillovers between the stock and currency markets of ten Asian economies from 2003 to 2014 period using a multivariate asymmetric GARCH model, such as a bivariate VAR-GARCH process based on an asymmetric version of the BEKK model. The empirical findings revealed that a negative shock had a greater influence on volatility than a positive shock of a similar magnitude, while global financial crisis has significantly influenced volatility transmission patterns. Beirne et al. (2013) investigated volatility spillovers and contagion from mature to emerging stock markets using tri-variate GARCH-BEKK models and suggested that spillover parameters change during turbulent while conditional variances in local markets rises, volatility in mature markets rises even much more, and this shift is the main factor behind the increase in conditional correlations.

Kumar et al. (2018) investigated volatility spillovers across Asian emerging stock markets using an asymmetric multivariate generalized autoregressive conditional heteroscedastic model. The authors concluded that multiple reforms, increasing financial transparency and decreasing restrictions on transactions have transformed these Asian markets into real attractions for international investors in the context of portfolio diversification strategy. Moreover, Withanage and Jayasinghe (2017) volatility spillovers between three emerging Asian stock markets such as Sri Lanka, India, and Pakistan for the sample period January 2004 to September 2014 using a trivariate BEKK - GARCH $(1,1)$ model and identified the existence of highly significant volatility spillovers from Sri Lanka to Pakistan and from India to Sri Lanka in both intraday and overnight sessions. Chitkasame and Tansuchat (2019) studied contagion effect on ASEAN stock markets by applying multivariate Markov switching DCC GARCH model and the empirical results indicated the existence of a strong contagion among selected stock markets.

$\mathrm{Xu}$ et al. (2018) investigated the linkage between illiquidity and volatility spillover effects in the case of 8 developed stock markets and argued that equity markets are interdependent, both in terms of volatility and illiquidity but illiquidity is a more relevant channel than volatility in propagating the shocks. The empirical findings indicated an increase in volatility and illiquidity spillover effects during the global financial crisis considering that the illiquidity in the US stock market played an essential role in influencing the behavior of other markets. Będowska-Sójka and Echaust (2019) have conducted an empirical study and revealed that there is a significant commonality in liquidity indices in the emerging European stock exchanges that strengthens during times of high volatility, especially during market crisis. 
Morales-Zumaquero and Sosvilla-Rivero (2016) studied intra-spillovers and inter-spillovers between stock markets in US, Euro area, Australia, Switzerland, Canada, UK and Japan from 1990 to 2015 using C-GARCH model. The findings revealed that long-run volatility relationships are stronger than the short-run linkages volatility with an enhancement during the post-global financial crisis period. Moreover, Quoreshi et al. (2019) examined equity market contagion in return volatility between 35 stock markets, including the US, UK, Japan, Euro Zone and BRICS countries and empirical findings revealed the evidence of contagion during the global financial crisis (GFC) and Euro Zone crisis (EZC) considering that the effects of shocks are not symmetric due to certain structural changes and there is contagion in volatility of stock index returns for predicted and unpredicted behaviours. In addition, Raczko (2015) investigated volatility contagion across stock markets in US, UK and Euro area (known as Euro Zone) and the empirical findings revealed that crash-risk premia exhibit higher correlations than non-crash risk premia, implying the existence of volatility contagion. Kenourgios (2014) examined volatility contagion across US and European stock markets during the Global Financial Crisis (GFC) and the Euro zone Sovereign Debt Crisis (ESDC). The empirical findings established the existence of contagion in cross-market volatilities.

Rejeb and Boughrara (2015) have investigated financial integration in emerging market economies and its impact on volatility transmission and contagion and have concluded that financial liberalization contributes significantly in amplifying the international transmission of volatility and the risk of contagion. Hol (2003) has provided Stochastic Volatility (SV) models as an applied alternative to the Generalised Autoregressive Conditional Heteroskedasticity (GARCH) models. Dutta et al. (2017) have investigated the effect of oil volatility shocks on global emerging market stock returns and have concluded that the OVX index shocks generate a high impact on emerging market equity returns. Rao et al. (2008) conducted an empirical study on modelling asymmetric volatility of Indian stock market using two different nonlinear asymmetric models, i.e. EGARCH and TGARCH models in order to estimate volatility of BSE 500 stock returns and concluded that selected financial time series exhibit leverage effect, volatility clustering and leptokurtosis.

Ahmed et al. (2018) investigated stock returns, volatility and mean reversion in emerging and developed financial markets and the empirical findings of ARCH and GARCH revealed that the value of likelihood statistics ratio is large, that entails the GARCH $(1,1)$ model is a lucrative depiction of daily return pattern, that effectively and efficiently capturing the orderly reliance of volatility. Fasanya and Akinde (2019) conducted an empirical study of return and volatility spillovers in the Nigerian emerging financial markets and concluded that the stock market returns are more susceptible to fluctuations in financial market, but also more vulnerable and risky due to the fact that it can be easily influenced by the fluctuations in both the currency and money markets.

Jebran et al. (2017) investigated volatility spillover among stock markets of Asia, such as: China, Pakistan, Hong Kong, Sri Lanka, and India by using an extended EGARCH model for the period 2007-2013 and suggested that integrations among financial markets in terms of volatility spillover exhibit low potential diversification opportunities for investors. The author selected 2 sub-periods, i.e. the pre-crisis period which is from $2^{\text {nd }}$ January, 2001 to $30^{\text {th }}$ July, 2007, and the post-crisis period which is from 1st August, 2007 to $31^{\text {st }}$ December, 2013. The 
empirical findings revealed the existence of bidirectional volatility spillover between stock markets of India and Sri Lanka, but also between Hong Kong and India in both sub-periods, while between Pakistan and India only in pre-crisis period, and in stock markets of Sri Lanka and Pakistan in post-crisis period. Silvia et al. (2019) investigated spillover effect between several Asian emerging markets such as: Indonesia, Malaysia, Thailand, India, China and Taiwan from May 13, 2011 to October 17, 2017 (a post- crisis sample period) using multivariate VAR model, Granger Causality test and Pearson Correlation. The empirical results led to the conclusion that there is a spillover effect in all sample stock markets in Asia considering the bidirectional relationship between Indonesian market and the other stock markets.

Majdoub and Sassi (2017) studied volatility spillover between certain Asian stock markets such as: China, India, Malaysia, Indonesia, Korea and Thailand using the Bivariate VARMABEKK-AGARCH model developed by McAleer et al. (2009), as an extension of the widely used univariate asymmetric (or threshold) GJR model, based on spillover and asymmetric effects. The authors find no evidence of short term volatility persistence in India, Indonesia and Malaysia, while GARCH model revealed no persistence in volatility spillover effect in long term from Chinese to Indian, Indonesian and Korean stock market. Moreover, Li and Giles (2015) investigated the linkages of stock markets across the USA, Japan and six Asian developing countries: China, India, Indonesia, Malaysia, the Philippines and Thailand over the period 1 January 1993 to 31 December 2012 and have empirically demonstrated the existence of unidirectional shock and volatility spillovers from the US market to both the Japanese and the other Asian emerging markets. Various empirical research studies have analyzed the contagion of volatility between certain developed stock markets such as US and/or UK, and some emerging markets in Africa and Asia. Giovannetti and Velucchi (2013) examined the spread of volatility effects between certain developed stock markets such as US and UK and other emerging markets such as China (Asia), Botswana, Kenya, Nigeria and South Africa (South Saharan Africa), Egypt and Tunisia (North Africa) for the sample period 2005-2012. The authors concluded that US and Kenya are "volatility creators" and South Africa and China are "volatility absorbers" considering that both US and China have a significant influence on the African stock markets. Taly (2015) examined return and volatility spillover between stock markets of US, Korea and Japan for the sample period from 2002 to 2010 and concluded that volatility transmission exists among these financial markets, which means increasing volatility in one financial market is a clear signal of increasing volatility in other financial markets. Baele (2003) investigated the existence of volatility spillovers between European and US stock markets, but although both the EU and US shock spillover intensity has increased over the 1980s and 1990s, the rise is more pronounced for EU spillovers, while empirical results indicated contagion from the US market to a number of local European stock markets during periods of high world market volatility.

Bahadur et al. (2017) investigated volatility spillover effect between stock markets in India, Japan (Asia), UK (Europe) and US (North America) and concluded that Indian stock market return is found to have long term relationship with market returns of US, UK and Japanese stock markets. The empirical findings revealed the existence of inbound volatility transmission from US market to Indian stock market, while Indian and UK stock market have bi-directional volatility transmission. Leung, Schiereck, and Schroeder (2017) examined 
volatility spillover between the equity markets of US (North America), UK (Europe) and Japan (Asia) using a GARCH model and suggested that pure contagion which is attributable to irrational investors' behavior and fundamental contagion which is measured by macroeconomic fundamentals explains the increased spillover during the global financial crisis. Hamao et al. (1990) investigated short-run interdependence of stock prices and volatility transmission patterns among developed stock markets in New York (US), London (UK) and Tokyo (Japan) using a univariate GARCH model. The empirical findings showed volatility spillovers from New York to Tokyo, London to Tokyo, and New York to London, but no evidence in another direction for the pre-crisis period (the stock market crash of October 19, 1987, also known as "Black Monday"). Girard and Biswas (2007) investigated the linkage between volatility and volume in 22 developed markets and 27 emerging markets, and identified a negative relation between expected volume and volatility in several emerging markets, due to the relative inefficiency in those particular markets.

\section{Empirical methodology and statistical data}

This paper includes a comparative empirical research between stock markets in certain developed and emerging economies. The empirical research analyzes the long-term behaviour of 7 selected developed stock market indices, i.e. IBEX 35 index (Spain), DJIA index (USA), FTSE 100 (UK), TSX Composite index (Canada), Nikkei 225 (Japan), DAX Index (Germany), CAC 40 (France) and 5 selected emerging stock market indices, i.e. BET index (Romania), WIG 20 index (Poland), BSE index (India), SSE Composite index (China) and BUX index (Hungary) from January 2000 to June 2018. The selection of countries intends to capture the behaviour of the most relevant stock markets from North America, Europe and Asia continents. In other words, these specific developed stock markets represent some of most impactful financial markets of selected continents. However, the random choice of emerging markets from Europe and Asia continents intends to explore and capture the relevance and impact of developed stock markets dynamics.

The econometric approach includes asymmetric GARCH models such as EGARCH and GJR which are performed in order to capture asymmetric volatility clustering and leptokurtosis based on abnormal volatility transmission and contagion patterns between emerging and developed stock markets. Augmented Dickey Fuller (ADF) test is employed to check stationary in financial series log returns for fitness of autoregressive models. To examine the correlation between series returns and co-movements, Spearman's correlation (rho) and Kendall's (tau) used that measures and compares series return movements and correlation along with ranking to relationship. Property of summary of statistics would represent mean returns, median, min and max, degree of Skewness and Kurtosis. Further, Generalized Autoregressive Conditional Heteroskedasticity $(\mathrm{GARCH})$ employed to measure volatility magnitudes from selected series returns. A class of univariate conditional volatility models particularly, GARCH, EGARCH and GJR relates standardise residuals to return shocks. Application of these three models is essential to understand the stochastic properties of selected financial markets. A study on regulatory condition and interpretation of asymmetry by Chang and McAleer (2017) applies all three univariate models to explore asymmetry properties. Tao 
and Green (2012) suggested that if volatility spillovers are combined with asymmetries, a bad news shock in either market may increase volatility and its persistence in both markets.

Financial market series returns have different stationary process i.e. unit root. It represents stochastic trend in financial series returns. This pattern requires to be stationary to employ estimation models. The continuously compounded daily returns are calculated using the log-difference of stock markets selected indices as follows:

$$
r_{t}=\ln \left(\frac{p_{t}}{p_{t-1}}\right)=\ln \left(p_{t}\right)-\ln \left(p_{t-1}\right),
$$

where $p$ is the daily closing price except for legal holidays or other events when stock markets have not performed transactions. The continuously compounded daily stock market returns are calculated using the log-difference of the closing prices of stock markets selected indices.

To compare movements of developing and emerging market with each-other and for ranking and accuracy in comparative measurement, Spearman and Kendall produce respectively. Spearman's rank correlation (rho) and Kendall's rank correlation (tau) in place of default Pearson's coefficient.

$$
R=1-\frac{6 \varepsilon d^{2}}{n^{3}-n} .
$$

The closer result of $\mathrm{r}$ between 1 to -1 , represents stronger likely correlation either positively or negatively respectively. However, result in 0 indicate no correlation among selected financial markets.

Our research study applies the hypothesis of covariance stationary as unconditional variance, while using this econometric structures:

$$
\begin{gathered}
\sigma^{2}=\operatorname{Var}\left(u_{t}\right)=E\left(u_{t}^{2}\right)=E\left(\omega+\alpha_{1} u_{t-1}^{2}+\beta_{1} h_{t-1}\right) \\
\sigma^{2}=\omega+\alpha_{1} E\left(u_{t-1}^{2}\right)+\beta E\left(h_{t-1}\right)=\omega+\alpha_{1} \sigma^{2}+\beta_{1} \sigma^{2} .
\end{gathered}
$$

The GARCH $(1,1)$ model represents the most accessible and robust design of the volatility family models (Engle, 2001). The GARCH $(1,1)$ model developed by Bollerslev (1986) is employed with the purpose off estimating the volatility returns of our sample cluster which includes both developed and emerging stock markets. GARCH $(1,1)$ model fundamentally means conditional variance which is highlighted as a linear function of its own lags. Moreover, conditional variance of all variables is necessary to be dependent upon previous lags. On the other hand, the first lag of squared residuals will generate mean equation and provides informations concerning volatility from previous time period.

Practically, GARCH $(1,1)$ model is characterized by the following key elements, i.e.: Mean equation and Variance equation. The Mean equation has the following form:

$$
r t=\mu+\varepsilon t,
$$

while Variance equation is the following:

$$
\sigma_{t}^{2}=\omega+\alpha \varepsilon_{1 t-t}^{2}+\beta \sigma_{1 t-1}^{2} .
$$


As a specific feature, the mean equation reveals the retuns of asset in time $(t)$ which is the sum of average return denoted by $\mu$, while residual returns were denoted by $\varepsilon t$. Moreover, variance equation assumptions indicate the fact that constant value is higher than 0 , followed by value of $\alpha$ and $\beta$.

$$
h_{t}=\omega+\alpha_{1} u_{t-1}^{2}+\beta_{1} h_{t-1} .
$$

GARCH $(1,1)$ represents symmetric model and does not capture leverage effect which is captured by asymmetric GARCH models i.e. EGARCH and GJR. Leverage effect indicates correlation of past returns with future volatility. Both employed asymmetric GARCH models, Exponential GARCH by Nelson and GJR estimates leverage effect. GJR GARCH by Glosten, Jagannathan and Runkle also estimates impact of news for selected financial markets. Negative news creates more pronounced effect on any financial market that and probable impact measurement can be interesting in a manner to get idea about elasticity of market movement during negative news reaction. EGARCH developed by Nelson (1991) captures asymmetric responses of time-vary variances to volatilty shocks and also ensures that variance is always positive.

$$
\log \left(\sigma_{t}^{2}\right)=\omega+\sum_{j-i}^{p} \beta i \log \left(\sigma_{t-i}^{2}\right)+\sum_{j-1}^{q} \alpha i \frac{\varepsilon i-t}{\sigma}{ }_{i-t}\left|\frac{-\sqrt{2}}{n}\right|-y i \frac{\varepsilon i-t}{\sigma i-t} .
$$

Another asymmetric model is GJR which is a similarvariant of threshold GARCH (TGARCH) and it was developed by Glosten, Jagannathan, and Runkle (1993) also measures stylized facts such as leverage effect and effect of news on stock markets. In this model there is only regression in mean equation which is constant.

$$
h t=\delta+\alpha_{1} e_{i-1}^{2}+\gamma d_{i-1} e_{t-1}^{2}+\beta_{i} h_{i-1},
$$

where $d_{t}$ represents two cases in case of 1 and 0 , where $e_{t}<0$, generates bad news and 0 , $e_{t}>0$ indicates good news. Further the value of alpha, Gamma and Beta are non-negative parameters satisfying condition similar to EGARCH model in otherwise manner.

\section{Empirical results and discussion}

We empirically examined the behaviour of stock price index databases for 7 developed and 5 emerging markets from 2000 to 2018. Emerging stock markets reacts comparatively at larger degree in case of positive or negative news impact than developed stock markets. In this research study, the category of developed stock markets includes the following: USA, UK, France, Canada, Spain, Germany and Japan. On the other hand, the category of emerging stock markets: includes Hungary, Romania, China, Poland and India. Graphical presentation of actual series returns from all sample market presented in Figure 1 that indicates actual stock market movement from January 2000 to June 2018 that represents selected group of developed and emerging markets. The following Figure 1 represents actual market movement over the time-frame.

Before last financial crisis DIJA trending above 10000 index level, just before crisis it has crossed 13000 and crises impacted to trend DIJA merely 8500 index point level. S\&P TSX 

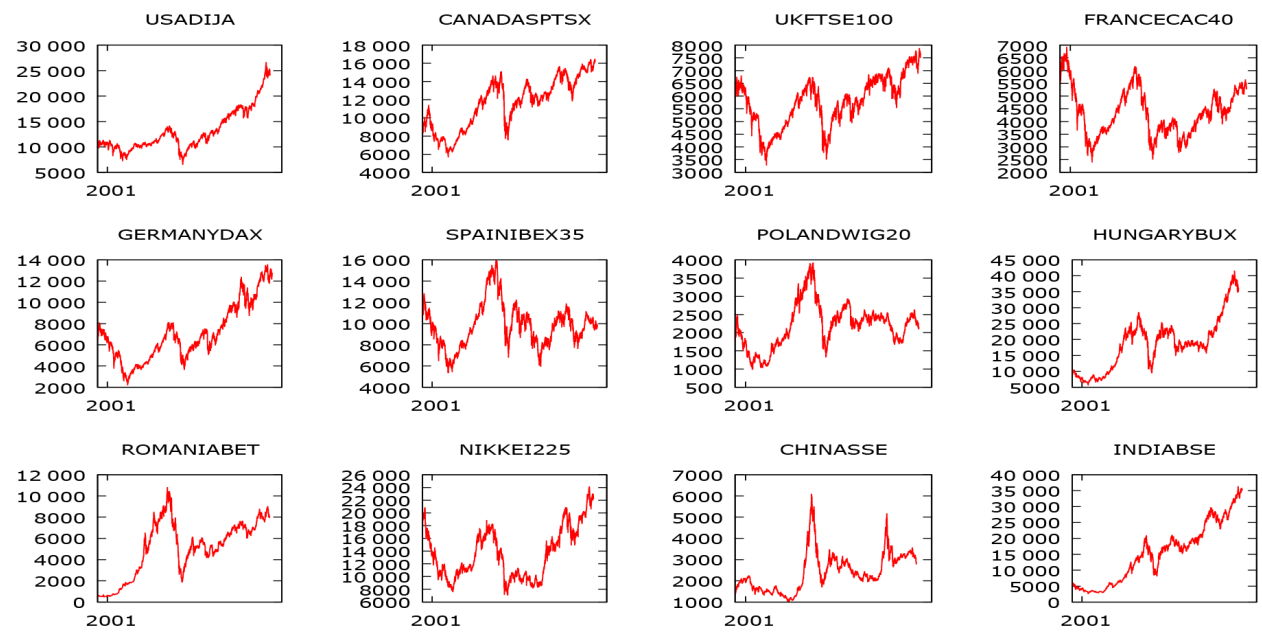

Figure 1 . The trend of selected stock market daily returns - individual graphics (source: author's own computation)

considered as specimen index to represent Canada that indicates strong upward transmitting pattern that moved index from 6000 points to above 14000 in just 6 years and crises impact resulted loss of over 6000 index points in less than two years. S\&P TSX market movement pattern after crises improved just 2000 more index points in almost 10 years i.e. 16000. FTSE100 that represents UK financial market trending lower than 3500 index points few years ago financial crises and reached 7000 index points just in few years, that move represents almost double the growth of FTSE100 financial markets. Financial crises impact resulted to bring back FTSE100 to level of 3500 and after more than 9 years index reached to 8000 points. France represents different pattern of financial market movements which is represented by CAC40 index that earlier trending 7000 index level points that reached to merely 2500 level in just two years i.e. 2002. Further grown up to almost 6000 points before crises and financial crisis again resulted CAC40 trending again 2500.

After global financial crisis CAC40 (France) index is trending between 5000 to 6000 level which is much lower than what it used to trend 18 years ago. The same appears in case of IBEX35 index that represents Spain which is also trending much lower than previous trending levels during the study period. Followed by Poland financial market WIG20 and BET index of Romania. The Asian emerging market which is represented by SSE index (China) also indicates negative trending position. However, another Asian financial market represented by BSE index (India) trending merely 5000 index points before financial crisis and reached almost 20000 index level before crisis. The crisis impact resulted trending BSE lower than 8500. Interesting part is rest of index movement that grown almost over 4 times and trending above 35000 index points. Followed by BUX that represents Hungary financial market that also trending 5000 points and grown up to 25000 before financial crises. The impact resulted in increasing BUX index trend at 10000 points. BUX breached 40000 points in post-crisis and grown almost 4 times. Same positive trending also found in DAX and NIKKEI225. 
The following figure presents the volatility pattern of selected stock market indices, such as:

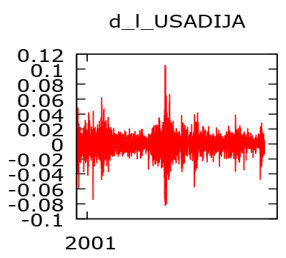

d_I_GERMANYDAX

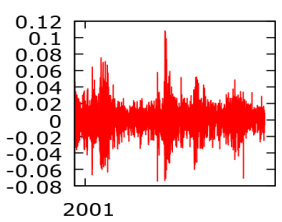

d_I_ROMANIABET

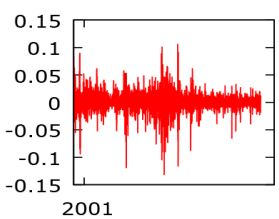

d_I_CANADASPTSX

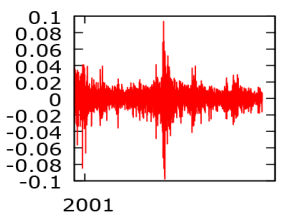

d_I_SPAINIBEX35

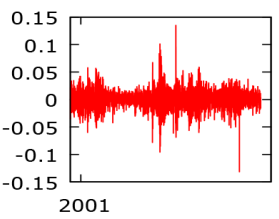

d_I_NIKKEI225

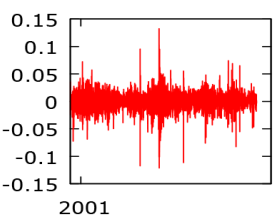

d_I_UKFTSE100

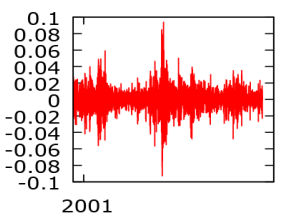

d_I_POLANDWIG20

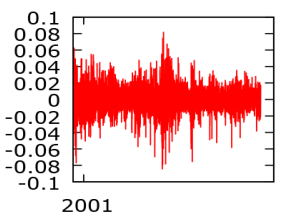

d_I_CHINASSE

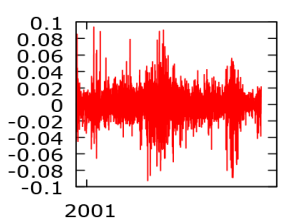

d_I_FRANCECAC40

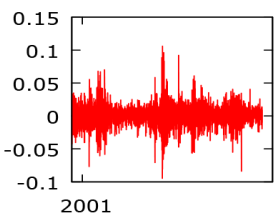

d_I_HUNGARYBUX

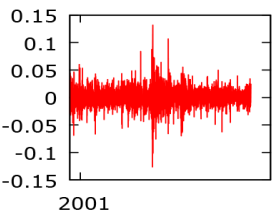

d_I_INDIABSE

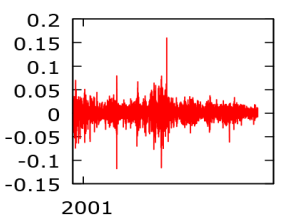

Figure 2. Volatility pattern of selected stock market indices (source: author's own computation)

Financial market generates shocks either positive or negative depending on the type of news. Shock depends on volume of trades that shows magnitude of impact in series returns (see Figure 2). It provides very significant outcome that all financial markets regardless developed or under developed have faced strong magnitude impacts during financial crisis that magnitude shocks scales at largest degree of negative and later positive degree. Particularly Canada and Germany have strongest degree of positive and negative shocks that appears on Figure 2. More volatility shocks even during normal trading sessions makes market more unpredictable and makes investment to high risk. Figure 2 captures volatility magnitude of selected twelve financial markets of American, European and Asian continent. Selected group of developed markets appears to have comparatively less degree of volatility shocks. Financial crisis impacts visible to all selected group markets. SSE Composite Index (China) found to have maximum volatility shocks containing high magnitude makes trades at very risk. WIG20 index (Poland) found second highest in escalating volatility. European emerging stock market indices such as BET (Romania) and WIG20 (Poland) captured more large magnitude shocks than positive. SSE Composite Index (China) was foundas the only stock market from selected cluster having maximum number of high magnitude positive shocks.

The following Table 1 includes the summary of statistics for all selected stock indices.

The results included in the previous table indicate basic statistics for proxy financial series of sample emerging and developed stock markets. The summary of statistics analysis indicates that all selected financial markets contain high degree of risk volatility that makes market move entirely upside down with negatively skewed returns and leptokurtosis effects, except financial asset returns of WIG20 index (Poland). It is being observed that TSX Composite 
index (Canada) exhibits the highest degree of negatively skewed returns, i.e. -0.65 and very high kurtosis, i.e. 9.79. Nevertheless, same followed by BET index (Romania) that represents kurtosis over 9 and second highest negatively skewed returns -0.50 . Property of summary of statistics tests residuals of selected countries represents out of normality based on observed skewness and degree of kurtosis that makes fat tails and leptokurtic patterns.

Table 1. Summary of statistics (source: author's computation using first log difference of selected financial data series from Jan 2000 to June 2018; ${ }^{*}$ Mean and Median returns are merely zero for all selected markets)

\begin{tabular}{|l|c|c|c|c|c|}
\hline \multicolumn{1}{|c|}{ Variable } & Min & Max & Skewness & Kurtosis & Std. Dev \\
\hline DIJA index - USA & -0.0820 & 0.1050 & -0.1116 & 8.3960 & 0.0113 \\
\hline TSX index - Canada & -0.0978 & 0.0937 & -0.6541 & 9.7967 & 0.0109 \\
\hline FTSE100 index - UK & -0.0926 & 0.0938 & -0.1423 & 6.4110 & 0.0117 \\
\hline CAC40 index - France & -0.0947 & 0.1059 & -0.0362 & 5.0749 & 0.0114 \\
\hline DAX index - Germany & -0.0743 & 0.1079 & -0.0221 & 4.3490 & 0.0148 \\
\hline IBEX35 index - Spain & -0.1318 & 0.0134 & -0.0814 & 5.9141 & 0.0147 \\
\hline WIG20 index - Poland & -0.0844 & 0.0815 & -0.1484 & 2.6228 & 0.0149 \\
\hline BUX index - Hungary & -0.1264 & 0.1317 & -0.0641 & 6.3069 & 0.0151 \\
\hline BET index - Romania & -0.1311 & 0.1056 & -0.5088 & 9.1682 & 0.0152 \\
\hline NIKKEI225 index - Japan & -0.1211 & 0.1323 & -0.4025 & 7.0476 & 0.0152 \\
\hline SSE index - China & -0.0925 & 0.0940 & -0.3501 & 5.0255 & 0.0156 \\
\hline BSE index - India & -0.1180 & 0.1599 & -0.2096 & 7.7318 & 0.0147 \\
\hline
\end{tabular}

Table 2. Normality ranking (source: author's computation)

\begin{tabular}{|l|c|c|c|}
\hline \multicolumn{1}{|c|}{ Variable } & Based on Skewness & Based on Kurtosis & Based on Std. Dev \\
\hline DIJA index - USA & 8 & 3 & 11 \\
\hline TSX index - Canada & 1 & 1 & 12 \\
\hline FTSE100 index - UK & 7 & 6 & 9 \\
\hline CAC40 index - France & 11 & 9 & 10 \\
\hline DAX index - Germany & 12 & 11 & 6 \\
\hline IBEX35 index - Spain & 9 & 8 & 5 \\
\hline WIG20 index - Poland & 6 & 12 & 4 \\
\hline BUX index - Hungary & 10 & 7 & 2 \\
\hline BET index - Romania & 2 & 2 & 1 \\
\hline NIKKEI225 index - Japan & 3 & 5 & 8 \\
\hline SSE index - China & 4 & 4 & 10 \\
\hline BSE index - India & 5 & & \\
\hline
\end{tabular}

A basic characteristic feature of emerging capital markets is that the distribution of continuously compounded returns deviates from the normal distribution or Gaussian distribution. The empirical analysis also focuses on Skewness and Kurtosis based on data distribution. 
Normality test ranking table (see Table 2) indicates three important measurement parameters i.e. skewness, kurtosis and degree of standard deviation. Skewness indicates symmetry or asymmetry in asset returns. In this study all sample financial series returns found negatively skewed. These distributions called asymmetric or asymmetrical distributions as they do not show any kind of symmetry. Rank distributions in Table 2 suggest that rank1 indicates highest degree of long left tail that indicates that Mean and Median are smaller than mode. Investors looking for long term investment needs to take care of degree of negatively skewed returns and high degree of kurtosis in series returns. For longer-horizon investors, emerging market stocks continue to provide significant diversification benefits even during periods of major stock market turbulences, because over longer horizons, stock prices do recover from a crash (Patel \& Sarkar, 1998).

Short and medium-term investors in particular need to observe at extremes otherwise they might get trap in market for long time than expected. For example (see Table 2) analysis of normality test indicates that all market asset returns are negatively skewed with high degree of kurtosis that almost guarantee that short and mid-term investors have to be careful about initial statistics. Early empirical research studies on volatility patterns (volatility spillovers) in developed and emerging market suggests that emerging financial markets try to follow pattern of developed financial market for example last financial crisis that has been followed by rest of world's financial markets. When one specific market follows the pattern of other financial market is called transmitting pattern that reflects in movement of follower market. We employed Spearman's (rho) and Kendall's correlation (tau) to measure correlation and similarity in market movement.

Spearman's correlation provides significant clarity to understand the transmitting pattern and dependency of one market over another. Several surprising outcomes derived by correlation that indicates that Germany's financial market DAX having highest correlation with movement of DIJA, USA. It indicates that DAX index of Germany follows financial market movement pattern of DIJA, USA. Asian emerging market of India, represented by BSE index follows more the S\&P/TSX Composite index of Canada more than DIJA of USA. On the other side Financial market of Spain, Poland, France and even China do not follow any developed or emerging financial market completely. This indicates that all these market have their own independent market movement pattern. Developed financial markets create less volatile impact in general and remain correlated for long term movements. For instance, financial markets of Germany, United Kingdom and Canada considering DAX index, FTSE100 index and TSX index, considering that the previous indices follow transmitting patterns of DIJA index (USA), except one of European index i.e. CAC 40 index (France). Emerging European markets that have greater ITP degree such as of IBEX 35 index (Spain) and WIG 20 index (Poland) from the rest of the European and American financial markets. Other European markets such as: BUX index (Hungary) and BET index (Romania) follow mixed country transmitting pattern. We have also tested the cross-correlations between selected stock indices and empirical results are insignificant. The statistical results are presented in Table 3. It provides significant relevance that indicates specific market mentioned above relates to market movement pattern for correlated financial market. 


\begin{tabular}{|c|c|c|c|c|c|c|c|c|c|c|c|c|}
\hline$\underset{s}{\stackrel{4}{s}}$ & מ & Z & 岇 & 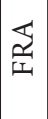 & 舀 & 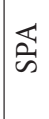 & O) & 兄 & $\mid \begin{array}{l}\sum_{0} \\
\not \approx\end{array}$ & 定 & 急 & 台 \\
\hline 㐏 & \begin{tabular}{|l}
$\vec{\infty}$ \\
$\infty$ \\
0 \\
0
\end{tabular} & 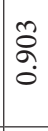 & $\begin{array}{l}\infty \\
0 \\
0 \\
0\end{array}$ & $\begin{array}{l}* \\
0 \\
0 \\
0\end{array}$ & $\begin{array}{l}\circ \\
\infty \\
0\end{array}$ & 竎 & 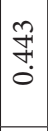 & $\begin{array}{l}n \\
\infty \\
0\end{array}$ & I & $\frac{n}{n ! n}$ & $\begin{array}{l}n \\
\hat{n} \\
0 \\
0\end{array}$ & \\
\hline 兄 & $\mid \begin{array}{l}2 \\
\tilde{n} \\
0 \\
0\end{array}$ & $\begin{array}{l}0 \\
0 \\
0 \\
0\end{array}$ & 点 & $\frac{d}{\tilde{m}}$ & $\vec{b}$ & $\mid \begin{array}{l}\hat{\gamma} \\
\text { in } \\
0\end{array}$ & $\begin{array}{l}\hat{\hat{n}} \\
\hat{n} \\
0\end{array}$ & $\begin{array}{l}10 \\
\hat{n} \\
0 \\
0\end{array}$ & $\begin{array}{l}0 \\
0 \\
0 \\
0 \\
0\end{array}$ & $\stackrel{\leftrightarrow}{\mathfrak{s}}$ & - & \\
\hline 定 & $\mid \begin{array}{l}\infty \\
\\
0 \\
0\end{array}$ & $\begin{array}{l}\hat{a} \\
\hat{L} \\
0\end{array}$ & $\begin{array}{l}2 \\
\hat{\Omega} \\
0\end{array}$ & 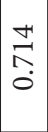 & $\begin{array}{l}\infty \\
\stackrel{\infty}{n} \\
\hat{0}\end{array}$ & $\begin{array}{l}n \\
\tilde{n} \\
0\end{array}$ & $\begin{array}{l}\vec{\infty} \\
\tilde{0} \\
0\end{array}$ & 芩 & $\mid \begin{array}{l}\tilde{n} \\
\tilde{n} \\
0\end{array}$ & - & & \\
\hline 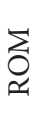 & $\mid \begin{array}{l}n \\
\hat{L} \\
0 \\
0\end{array}$ & \begin{tabular}{l}
\multirow{H}{*}{} \\
$\infty$ \\
0 \\
0
\end{tabular} & $\begin{array}{l}\stackrel{0}{0} \\
\stackrel{0}{0}\end{array}$ & $\stackrel{9}{\stackrel{0}{0}}$ & $\begin{array}{l}\infty \\
1 \\
0\end{array}$ & $\mid \begin{array}{l}n \\
\infty \\
n \\
0 \\
0\end{array}$ & $\begin{array}{l}2 \\
\infty \\
\hat{0} \\
0\end{array}$ & $\begin{array}{l}\infty \\
\infty \\
\\
0\end{array}$ & - & & & \\
\hline 朰 & $\mid \begin{array}{l}\hat{n} \\
\hat{0} \\
0\end{array}$ & $\begin{array}{l}n \\
0 \\
0 \\
0\end{array}$ & în & $\begin{array}{l}0 \\
0 \\
0 \\
0\end{array}$ & $\begin{array}{l}1 \\
0 \\
0 \\
0 \\
0\end{array}$ & $\frac{2}{\tilde{m}}$ & 俈 & - & & & & \\
\hline $\overrightarrow{0}$ & $\vec{z}$ & $\begin{array}{l}\infty \\
\stackrel{0}{0} \\
0\end{array}$ & $\mid \begin{array}{l}n \\
\hat{n} \\
0 \\
0\end{array}$ & $\begin{array}{c}\hat{N} \\
\tilde{n} \\
0\end{array}$ & 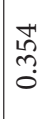 & $\begin{array}{c}\not \\
0 \\
0\end{array}$ & - & & & & & \\
\hline 蛋 & $\underset{\sigma}{\sigma}$ & $\begin{array}{l}\vec{n} \\
\hat{n} \\
0\end{array}$ & $\mid \begin{array}{l}0 \\
0 \\
0 ? \\
0\end{array}$ & $\mid \begin{array}{l}0 \\
0 \\
0 \\
0 \\
0\end{array}$ & 命 & - & & & & & & \\
\hline 寽 & $\begin{array}{l}\stackrel{2}{2} \\
\hat{\alpha} \\
0\end{array}$ & $\begin{array}{l}\vec{n} \\
\infty \\
0\end{array}$ & $\begin{array}{l}\infty \\
\infty \\
0 \\
0\end{array}$ & 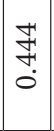 & - & & & & & & & \\
\hline$\underset{\mid}{\overleftrightarrow{\underline{I}}}$ & 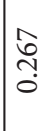 & 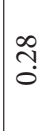 & $\begin{array}{l}m \\
0 \\
0 \\
0\end{array}$ & - & & & & & & & & \\
\hline 光 & $\mid \begin{array}{l}0 \\
1 \\
0 \\
0 \\
0\end{array}$ & $\begin{array}{l}9 \\
\infty \\
0\end{array}$ & - & & & & & & & & & \\
\hline Z & $\begin{array}{l}0 \\
\infty \\
0 \\
0\end{array}$ & - & & & & & & & & & & \\
\hline $\begin{array}{l}\mathbb{W} \\
\text { م }\end{array}$ & - & & & & & & & & & & & \\
\hline
\end{tabular}


CAC 40 index (France) has generated ITP pattern that makes market more volatile despite of being developed financial market. Further, compare to other financial market ITP pattern makes it more difficult to predict. Developed financial market of Japan NIKKEI 225 index also created ITP which is partly followed by CAC 40 index (France) and FTSE100 index (UK) and DIJA index (USA). Emerging Asian financial market of SSE index (China) and BSE index (India) have separate transmitting pattern. SSE index (China) has created ITP that is a mixture of S\&P/TSX Composite index (Canada), DAX index (Germany) and BET index (Romania). It is not following the transmitting pattern of other American or Asian financial markets. BSE index(India)exhibits complex financial transmitting pattern that includes a mixture of patterns of both American and European developed and emerging stock markets such as S\&P TSX Composite index (Canada), DIJA index (USA), DAX index (Germany) and BUX index (Hungary).

It is important to test the hypothesis that process has unit root at 1 that is AR poly-nominal $\varnothing(Z)=0$, when $z=1$. We test $H 0: y=0$ by estimating $y$ in regression of $\nabla x t$ on $x t-1, \ldots \nabla x t-p+1$ that create $t y=\gamma / s e(\gamma)$. This test is known as Augmented Dickey-Fuller test (ADF) and processed on all financial series returns before implementing GARCH and GARCH type models. Test results for all selected financial market provides significant output that rejects $H 0$ and confirms series return stationary.

The selected developed and emerging stock market is highly volatile. For example, the results of summary of statistics suggested the existence of left tailed negative skewed returns, and abnormal kurtosis which generates leptokurtic effects. The following Table 4 provides details regarding the coefficient of mean and variance equation considering GARCH family models.

Table 4. Summary of GARCH family models (source: author's computation)

\begin{tabular}{|c|l|c|c|c|c|c|}
\hline Model & Variable & constant & Omega & alpha & gamma & beta \\
\hline \multirow{5}{*}{ GARCH (1,1) } & USA & $6.08259 \mathrm{E}-05$ & $1.75584 \mathrm{E}-08$ & 0.111408 & - & 0.877089 \\
\cline { 2 - 7 } & Canada & $4.55343 \mathrm{e}-05$ & $7.52461 \mathrm{e}-09$ & 0.0820925 & - & 0.913008 \\
\cline { 2 - 7 } & UK & $4.12239 \mathrm{e}-05$ & $2.20800 \mathrm{e}-08$ & 0.110416 & - & 0.877922 \\
\cline { 2 - 7 } & France & $5.95278 \mathrm{e}-05$ & $2.82337 \mathrm{e}-08$ & 0.0979569 & - & 0.894709 \\
\cline { 2 - 7 } & Germany & $7.91328 \mathrm{e}-05$ & $2.72030 \mathrm{e}-08$ & 0.0911415 & - & 0.899462 \\
\cline { 2 - 7 } & Spain & $5.65160 \mathrm{e}-05$ & $2.96790 \mathrm{e}-08$ & 0.102778 & - & 0.888919 \\
\cline { 2 - 7 } & Poland & $3.41924 \mathrm{e}-05$ & $2.77211 \mathrm{e}-08$ & 0.0563812 & - & 0.936592 \\
\cline { 2 - 7 } & Hungary & $6.63142 \mathrm{e}-05$ & $4.12552 \mathrm{e}-08$ & 0.0916687 & - & 0.892538 \\
\cline { 2 - 7 } & Romania & $8.53405 \mathrm{e}-05$ & $4.39546 \mathrm{e}-08$ & 0.190467 & - & 0.817264 \\
\cline { 2 - 7 } & Japan & $5.71752 \mathrm{e}-05$ & $7.97739 \mathrm{e}-08$ & 0.113091 & - & 0.856853 \\
\cline { 2 - 7 } & China & $3.11940 \mathrm{e}-05$ & $2.14722 \mathrm{e}-08$ & 0.0701535 & - & 0.927913 \\
\cline { 2 - 7 } & India & $8.51939 \mathrm{e}-05$ & $1.79898 \mathrm{e}-08$ & 0.101552 & - & 0.895256 \\
\hline \multirow{5}{*}{ GJR (1, 1) } & USA & $2.45688 \mathrm{E}-05$ & $1.88374 \mathrm{E}-08$ & 0.0453287 & 0.991971 & 0.893412 \\
\cline { 2 - 7 } & Canada & $2.54979 \mathrm{E}-05$ & $9.74035 \mathrm{E}-09$ & 0.0559582 & 0.436022 & 0.921065 \\
\cline { 2 - 7 } & UK & $-2.98047 \mathrm{e}-05$ & $1.85432 \mathrm{e}-06$ & 0.0422546 & 0.998227 & 0.898075 \\
\cline { 2 - 7 } & France & $3.86603 \mathrm{e}-05$ & $2.31968 \mathrm{e}-06$ & 0.0414578 & 0.993883 & 0.905525 \\
\hline
\end{tabular}


End of Table 4

\begin{tabular}{|c|c|c|c|c|c|c|}
\hline Model & Variable & constant & Omega & alpha & gamma & beta \\
\hline \multirow{8}{*}{$\operatorname{GJR}(1,1)$} & Germany & $2.87641 \mathrm{e}-05$ & $3.10365 \mathrm{e}-08$ & 0.0380765 & 0.988720 & 0.910622 \\
\hline & Spain & 0.000107180 & $2.52156 \mathrm{e}-06$ & 0.0491812 & 0.727603 & 0.911682 \\
\hline & Poland & 0.000112050 & $1.92312 \mathrm{e}-06$ & 0.0522658 & 0.180311 & 0.937020 \\
\hline & Hungary & 0.000378091 & 4.96918-06 & 0.0842690 & 0.244517 & 0.888475 \\
\hline & Romania & 0.000668357 & $4.14118 \mathrm{e}-06$ & 0.195553 & 0.0499635 & 0.804018 \\
\hline & Japan & 0.000215054 & $8.61089 \mathrm{e}-06$ & 0.101248 & 0.295657 & 0.849602 \\
\hline & China & 0.000154263 & $1.44710 \mathrm{e}-06$ & 0.0685281 & 0.0802773 & 0.927431 \\
\hline & India & $5.83077 \mathrm{e}-05$ & $2.22657 \mathrm{e}-08$ & 0.0937341 & 0.246413 & 0.893505 \\
\hline \multirow{12}{*}{$\begin{array}{l}\text { EGARCH } \\
(1,1)\end{array}$} & USA & $2.75974 \mathrm{E}-05$ & -0.461355 & 0.150401 & -0.136722 & 0.975197 \\
\hline & Canada & 0.000233027 & -0.220585 & 0.124604 & -0.0823699 & 0.987089 \\
\hline & UK & $-5.49972 \mathrm{e}-05$ & -0.822116 & 0.370545 & -0.122324 & 0.958723 \\
\hline & France & $-5.69421 \mathrm{e}-05$ & -0.256093 & 0.103595 & -0.143193 & 0.980285 \\
\hline & Germany & 0.000191069 & -0.281832 & 0.121040 & -0.115860 & 0.978710 \\
\hline & Spain & $1.88156 \mathrm{e}-05$ & -0.269085 & 0.121274 & -0.108167 & 0.980070 \\
\hline & Poland & 0.000141028 & -0.185774 & 0.118456 & -0.0334935 & 0.989025 \\
\hline & Hungary & 0.000342245 & -0.330448 & 0.169844 & -0.0555042 & 0.976805 \\
\hline & Romania & 0.000656194 & -0.593028 & 0.360117 & -0.0280178 & 0.963083 \\
\hline & Japan & 0.000334034 & -0.636245 & 0.234421 & -0.0812378 & 0.946785 \\
\hline & China & 0.000212135 & -0.195349 & 0.152610 & -0.0199529 & 0.990268 \\
\hline & India & 0.000491 & -0.359701 & 0.206589 & -0.0755174 & 0.977223 \\
\hline
\end{tabular}

This empirical research study is based on the analysis of 12 particular countries that includes American, European and Asian developed and emerging economies. GARCH and GARCH type model have been employed to measure magnitude of volatility. All coefficients for mean and variance equation are significant at least at 5\% level. Developed stock market indices such as Dow Jones Industrial Average (USA), FTSE100 (UK), TSX (Canada), DAX (Germany), CAC40 (France), and NIKKEI225 (Japan) indicate the presence of a mixed movement pattern that includes unpredictable ups and downs in series returns, consist leverage effect (asymmetry) and high volatility. Nevertheless, emerging stock markets of European and Asian economies found gambling pattern, high magnitude shocks, persistent volatility and leverage effect.

The empirical results are explained individually for each selected country, as follows:

\subsection{Empirical results for USA:}

Daily closing asset price of DIJA (USA) considering 4641 observations of daily closing asset price processed through various statistics to measure normality, volatility and series movement pattern. Calculated estimates for DIJA index (USA) series return revealed the strongest positive movement market among developed economy group. Entire series calculations for Mean and Median resulted merely zero (See summary of statistics DIJA - USA). In addition 
to negatively skewed return (-0.1116) and high degree of kurtosis (8.3960), DIJA (USA) series transmitted from trading level of 6000 to 25000 , that almost over 4 times. GARCH $(1,1)$ model fitted to series returns, while $\operatorname{EGARCH}(1,1)$ and GJR $(1,1)$ models performed on residuals that ensure presence of asymmetry or leverage effect. DIJA (USA) ranked based on Skewed return, Degree of Kurtosis and Standard Deviation at level 8, 3, and 11 in ranking of all country. This indicates that comparative statistical outcome of DIJA (USA) series return based on property of summary makes DIJA index the second lowest degree of standard deviation.

\subsection{Empirical results for Canada:}

The S\&P TSX composite index containing 4643observations of daily closing asset price considered for Canada. GARCH $(1,1)$ indicates alpha (0.08) compared to $(0.11)$ for USA series returns. The series transmitted up to and over 15000 points from previously trading 8000 during financial crisis. S\&P TSX composite index of Canada, only series return that holds first rank in having highest degree of negative skewed return and highest degree of kurtosis (9.79) makes long left fat tail amongst sample of 12 countries. Statistical property of GJR and EGARCH confirms presence of leverage effect in series returns. S\&P TSX composite index also holds second rank in transmitting pattern growth among developed economy group. Correlation for S\&P TSX composite index relates $82 \%$ correlation of TSX with DIJA series returns. Interestingly some of emerging financial markets such as India, China, Hungary, Romania follow transmitting pattern of S\&P TSX composite index more than DIJA of USA, including financial market of Spain. With the exception of UK, Germany and Japan all sample countries follow higher degree of transmitting pattern of S\&P TSX composite index (Canada).

\subsection{Empirical results for UK:}

FTSE100 index (UK) is considered as specimen using 4677 daily observations of daily closing asset price. FTSE100index (UK) is used for estimating volatility ratio, volatility magnitude and correlation of series along with dependency of other financial market on movement of FTSE100. Series return fitted perfectly in GARCH $(1,1)$ compare to asymmetry models that confirms asymmetry. UK stands $7^{\text {th }}$ rank in negatively skewed return, $6^{\text {th }}$ rank in high kurtosis and $9^{\text {th }}$ on degree of standard deviation. Like other developed market FTSE100 also travelled its trading range from 3500 to over 7000 in the context of recent global financial crisis. NIKKEI225 index of Japan correlated to FTSE100 index at 79.9\% which is highest amongst all correlation with NIKKEI225 index. In particular, Germany financial market follows $88 \%$ of movement pattern of FTSE100 (UK) followed by BSE index (India) as 79\%. It is important to note that UK market correlated to DIJA index (US) at $82 \%$.

\subsection{Empirical results for France:}

CAC40 index is considered as specimen using 4704 daily observations of daily closing asset price. Series return of CAC40 index transmitted from trading from 2500 (after GFC) and breached 5000 points. However, summary of statics property indicates 11, 9 and 10 rank for negatively skewed return (-0.03), ex. kurtosis (about 5) and third lowest degree of standard 
deviation. Movement of series returns from 2000 to 2018 and appearance of summary of statistics provides different view. GARCH $(1,1)$ fitted well to series returns compared to EGARCH and GJR. Further, asymmetry found in series return. Low degree of standard deviation and minor negatively skewed return indicates that asset price remains either steady for longer period of time after investment or hardly moves suddenly. However, several negative and positive high magnitude shocks found during study period that has moved index to more than double after crisis. Spearman's correlation confirms that CAC40 index (France) does not absorb more changes from US or Canada market which is $<30 \%$, whereas, correlate more than $60 \%$ to changes in UK market.

\subsection{Empirical results for Germany:}

While compared to other non-Asian markets such as Poland, Spain or France, including UK and USA the transmitting pattern for DAX (specimen index for Germany) stands entirely different. The total 4696 daily observations considered from January 2000 to June 2018 excluding public holidays and assuming five days a week market. DAX index used trade between 2500 to 5000 earlier global financial crisis and reached merely 8000 index points before impact. The impact resulted DAX index to trade at level of about 4000 which makes about $50 \%$ of loss of index asset value. It is important to note that 4000 points are still higher than it used to trade before just rise of impact crisis. In particular, the market moved from below level of 2400 to over 13500 in selected time period, where from almost 4000 to 13500 jumped in past 9 years. DAX indexis also one which was found with lowest degree of negative skewed returns (-0.02) and slight higher degree of kurtosis (4.34). By looking at series pattern of DAX index, it shows strong upward trend. Nevertheless, it also reflects high magnitude shocks at negative and positive sides up to $(0.10)$ magnitudes. GARCH $(1,1)$ model fitted perfectly for DAX index. GJR $(1,1)$ and $\operatorname{EGARCH}(1,1)$ models also fitted to asset returns. Asymmetric GARCH models confirm the presence of leverage effect in DAX index (Germany) series returns.

\subsection{Empirical results for Spain:}

IBEX35 index (Spain) is considered for the empirical analysis using 4705 observations of daily closing asset price. The series return of IBEX35 index is amongst top in sample in terms of highest traded index points before the period of global crisis. In particular, the period before financial crisis from 2002 to 2008 IBEX35 index traded merely 6000 to make lifetime high with strong upward trend that breached 16000 index levels within five years. The global financial crisis impacted very strongly that created fall of IBEX35 index from 16000 to about 6500 with high to very high negative magnitude shocks. Average and mean return found negatively skewed (0.08) and excess kurtosis of 5.91. It is important to note that two major shocks have been identified in series return of IBEX35 index of which one represent negative that exceeds degree of $(-0.10)$ in recent past and one positive shock that exceed $(+0.10)$ magnitude. There are several sudden shocks found in financial series return of IBEX35 index of which one with highest negative shock of magnitude level exceeding -0.10 in recent past. In addition to correlation of IBEX35 index financial market movement that only correlated to over $60 \%$ degree with France (68\%), whereas series returns are only 
$19 \%$ correlated with market movement of DIJA (USA). However, it matches to over 53\% to S\&P TSX index of Canada.

\subsection{Empirical results for Poland:}

WIG20 index is considered as specimen for Poland considering 4633 daily closing price observations. WIG20 index traded between 1000 to 1500 from 2001 to 2003 and exhibits an impressive growth in the next five years that generated a jump of almost 3 times to reach new trading level of 4000 which is the highest in our sample period. Global financial crisis impacted very strongly to WIG20 index and damaged interest of investors that resulted asset loss of over 2500 points. Post financial crisis recovery resulted growth of only 1200 points merely $80 \%$ from low level. Post jump correction indicates loss of investor's confidence in WIG20 index. None like others, WIG20 index found index movement pattern highly correlated with Spain up to $81 \%$ and gives least weightage to any changes and movements in US only $31 \%$. S\&P TSX composite index (Canada) is correlated second highest at correlation of $70 \%$, whereas UK at 55\%. WIG20 series returns are only from sample countries that does not have higher degree of kurtosis and controlled at degree of 2. 62. However, WIG20 series returns negatively skewed returns at -0.14 and $0.0149 \operatorname{SD}$. GARCH $(1,1)$ confirmed persistence in volatility and fitted well to series returns. Asymmetric GARCH models confirm that asset returns responds for longer time to negative events.

\subsection{Empirical results for Hungary:}

In this research study BUX index represents Hungary by considering daily closing price observations counts 4471. Series return of BUX index that represents Hungary generated distinguished itself from rest of European markets. Investor's confidence in stock market of Hungary (BUX index) was very strong as market breached level of 25000 from 5000 in 6 years before the global financial crisis. Further, financial crisis created fall of 10000 points which recovered within next 3 years. The index kept growing to make new lifetime high achievements and reached to 40000 trading level. This represents an increase from 4000 to 5000 during the sample period. BUX index return series have been identified as highly correlated to S\&P TSX composite index (Canada) at degree of 76\%, followed by DJIA index (US) at $73 \%$ and FTSE100 index (UK) at 57\%. However, BUX index found higher correlated in series transmitting pattern of Germany at $68 \%$ compared to UK. Least followed market that correlated only $10 \%$ for CAC40 index (France). Hungary series returns are minor negatively skewed at -0.06 and kurtosis 6.30. BUX index stands forth rank at $0.0151 \mathrm{SD}$. GARCH $(1,1)$ model fitted well to asset returns at significance level of 5\%. Moreover, EGARCH $(1,1)$ and GJR $(1,1)$ models confirm the presence of leverage effect in series returns that ensures that like other stock markets, the series return of BUX index (Hungary) also responds more to negative news effect.

\subsection{Empirical results for Romania:}

BET index considered as specimen index of Romania consisting 4621 daily stock price observations. Stock market of Romania follows transmitting pattern of Canada that correlated at degree of $84 \%$, followed by Poland at $78.9 \%$ and Hungary $78.6 \%$. Dow Jones Industrial 
Average of US is correlated at degree of $65 \%$ followed by UK index $60 \%$. CAC40 of France is lowest observed market that correlated at 19\%. BET index assessed for summary of statistics and property suggests that asset returns are second highest negatively skewed return $(-0.50)$ along with second highest kurtosis (9.16) and third highest degree of standard deviation (0.0152). Like no other BET index provides evidence of historic growth in index returns that transmitted BET index trading from three digits lower than 500 to breached level of 10000 index points in just six years. This event is noted as highest financial market growth at least among rest of selected countries. Global financial crisis impacted heavily on BET index (Romania) movement and found much weaker market movement after financial crisis. Impact resulted BET index to trade merely 2000 and recovered 6000 points of loss. Financial market of Romania also provides history of several negative and positive magnitude shocks that exceeds 0.5 and some of even exceeds 0.10 of magnitudes. GARCH $(1,1)$ model fitted better to return series compared to asymmetric GARCH models.

\subsection{Empirical results for Japan:}

NIKKEI225 index is official represent financial market of Japan covering 4603 daily closing observations. Japan's financial market has suffered asset loss several times with many reasons. Even long before financial crisis the index being traded over 20000 index points. NIKKEI225 index bear asset loss of over 12000 long before GFC that resulted index to trade at level of 8000 points. However, being developed financial market and expectations of investors resulted recovery of 10000 points in just three years. Financial crisis impacted NIKKEI225 index again to trade at level of lower than 8000 from 18000. In particular, impact analysis indicates that asset loss caused by global financial crisis is lower than loss impacted earlier period from year 2000 to 2002. Transmitting pattern of NIKKEI225 index found highest correlated with market movement of UK at degree of $79.9 \%$ followed by US at $73 \%$ and Germany at $75 \%$. It is noticed that NIKKEI225 index market movement highly correlated with DAX index of Germany than DIJA index of US. Japan's financial market is unique to follow market movement of France at degree of $71 \%$ and SPAIN at $51 \%$. Least correlation found with market movement of Poland which is 38\%. Japan's NIKKEI225 index holds second rank in high degree of standard deviation (0.0152), fifth in excess kurtosis 7.04 and third in negatively skewed return at $(-0.40)$. EGARCH $(1,1)$ and GJR $(1,1)$ models fitted well to series return and found presence of leverage effects. $\operatorname{GARCH}(1,1)$ model fitted perfectly to asset returns and identified NIKKEI225 index with high and persistent volatility.

\subsection{Empirical results for China:}

Shanghai Stock Exchange (SSE) index (China) is an official financial market indicator and considered for study based on 4571 daily closing price observations. An independent transmitting pattern found in series return of SSE index during 2000 to 2018 established that SSE China does not follow any market over 70\%. It found correlated highest with market movement of Canada at $67 \%$ which is followed by Germany at $61 \%$ of correlation. More significant correlation found with Romania $60 \%$, Spain $57 \%$ and even Poland at 55\% compared to DIJA of USA at $52 \%$ and UK 53\%. Lowest degree of correlation found with France which is $31 \%$ correlated. Shanghai Stock Exchange (SSE) index assessed with its summary 
of statistics property and found with highest standard deviation 0.0156 that ranks on top of SD ranking and forth in negatively skewed returns $(-0.35)$, whereas kurtosis ranked series returns of SSE China at tenth at degree of 5.02. Strongest boom and high rise of SSE identified before financial crisis where indexed jumped from merely 1000 to 6000 points in three years. An index level of 6000 which was earlier to GFC identified as historic high. Financial market of China recovered asset damage from global financial crisis over $80 \%$ till 2016 but other economic and global matter result further correction that resulted index again to trade around 3000 points. GARCH $(1,1)$ fitted well to series returns of SSE China compared to fitness of asymmetry GARCH models. Nevertheless, presence of leverage effect is confirmed by EGARCH $(1,1)$ model and also GJR $(1,1)$ model.

\subsection{Empirical results for India:}

Bombay Stock Exchange (BSE) index is an official financial indicator for India and have been considered with 4568 daily closing observations from January 2000 to June 2018. It is found that BSE index jumped from 5000 points to 35000 index level within study period. BSE index traded about 20000 before GFC impact and resulted impact to trade BSE at level of lower than 8500. BSE is only index that could recover global financial crisis impact earliest and grown further in immediate years. There are several unpredictable positive shocks resulted up to 0.15 magnitudes which is highest level of magnitude shocks from rest of sample countries. The property of summary of statistics indicates -0.20 negatively skewed returns where 7.73 kurtosis that makes leptokurtic impact on asset returns. BSE, an Indian financial market is highly correlated with Canada's S\&P TSX $90 \%$ followed by DIJA index(USA) at $88 \%$ and DAX index (Germany) at $86 \%$. It is found abnormal when it is noted that BSE also correlated with emerging European market of Hungary at $83 \%$ and Romania at $74 \%$. It further makes more surprise when it is noted that emerging European market correlation is higher than developed market of FTSE100 index (UK) which is correlated at 70\%. At the other side, it is CAC40 of FRANCE that least correlated with market movement of Bombay Stock Exchange (BSE) index at 4\%. BSE index closing returns fitted perfectly in $\operatorname{GARCH}(1,1)$ and also fitted well in asymmetric GARCH models i.e. EGARCH $(1,1)$ and GJR $(1,1)$ but confirms high and persistence volatility and also the presence of leverage effects in series returns.

What do your empirical results mean in terms of GARCH and GARCH type models? Symmetric GARCH $(1,1)$ by Bollerslev $(1986)$ fitted on all selected group of developed and emerging financial markets. We have forecasted selected 12 financial markets representing groups of American, European and Asian developed and emerging markets. GARCH $(1,1)$ property result indicates higher forecasting ability and efficiency for model fitness. It is found that Asian emerging market specimen SSE Composite index (China) and BSE Sensex (India) have most persistent in volatility. The GARCH $(1,1)$ estimate expands 0.998067 and 0.996808 respectively for SSE Composite Index and BSE Sensex. North American specimen index S\&P TSX Index (Canada) found highest persistent in selected groups of developed markets, whereas WIG20 (Poland) and IBEX35 (Spain) found most persistent in volatility financial market from Europe continent. The most and persistent in volatility all selected financial markets are estimated by $\operatorname{GARCH}(1,1)$ and its asymmetric effect i.e. reflection of past volatility movement on present explored by Exponential GARCH (EGARCH) and GJR 
GARCH. All selected market found presence of leverage effect explored by GARCH asymmetric models EGARCH and GJR. This indicates that regardless being developed or emerging market, the past volatility last for longer period of time. It stretches negative movement for longer duration and create more shocks negative than positive.

GJR forecasts impact of positive news for developed and emerging markets. Statistical property of GJR indicates that BET (Romania) an European emerging market found with highest degree of alpha, 0.195553 followed by Asian developed specimen NIKKEI 225 (Japan) 0.101248 . It provides information that mentioned both countries react more on positive news compared to rest sample countries. Among the application of three models, GARCH $(1,1)$ is more efficient and suitable to estimate volatility for selected group of countries. Application of GARCH $(1,1)$ objected to estimate the volatility pattern in American, European and Asian markets. Whereas to identify, whether any of these financial market have impact of past volatility on present day volatility being explored by employing asymmetric EGARCH and GJR model. A study on forecasting S\&P 100 index volatility using asymmetric models EGARCH and GJR models achieve most accurate volatility forecast by Liu and Hung (2010) found evidence that strongly demonstrate asymmetric components. Dutta (2014) employs GARCH, EGARCH and GJR to model symmetric and asymmetric volatility, the finding suggests that positive shocks are more common than negative shocks. Volatility estimates for emerging markets provides high and frequent positive and negative magnitudes. Particularly, Asian emerging markets i.e. China and India found most volatility in nature compared to European emerging markets. The developed financial market indices for North America and Europe found less volatility and captures least impact of positive news. It is found that American market Dow Jones Industrial Average movement create transmitting pattern on European and Asian markets, except least transmitting pattern on Spain and France.

\section{Conclusions}

Our research paper provides additional empirical evidence regarding investment opportunities and risk management based on international portfolio diversification generated by abnormal volatility transmission and contagion patterns between emerging and developed stock markets. A diversified investment portfolio can generate significant returns and minimize risk exposure. Diversification plays an essential role in case of long-term investment strategy. Moreover, this empirical study contributes to the scarce existing literature on volatility spillover effects and contagion patterns between emerging and developed stock markets geographically dispersed on different continents. Most previous empirical studies focus on one or more countries in the same region. Financial market volatility, whether has risen from developed or emerging economies, is widely estimated with autoregressive models consistent with heteroskedasti city that measures volatility. While volatility of one country reflects on other country which is also measured by correlation matrix, the transmission pattern can be mapped. Our findings are in line with other empirical evidence previously mentioned in the literature review section.

GARCH and GARCH type models have been applied in order to estimate volatility for selected developed and emerging financial markets of North America, Europe and Asia. 
Models used for financial market series returns as it incorporates the past volatility behaviour on present movements. GARCH models explore generation of financial series given the exogenous and explanatory variables. $\operatorname{GARCH}(1,1)$ provides detail for symmetric distribution for selected American, European and Asian environmental modelling. An asymmetric GARCH models reveals different magnitude effect of past volatility on present day volatility. Further, application of GJR provides information that how developed and emerging market perceive news impact on volatility. This research paper explores that North American market have highest transmitting pattern in volatility i.e. Dow Jones Industrial Average and S\&P TSX specimen of US and Canada. Germany is the only country from the European continent which captures transmitting pattern of FTSE 100 (UK). None of Asian emerging market captures transmitting pattern of Asian developed market. This research study is based on a complex empirical analysis of a consisting sample cluster of 12 countries that includes North American, European and Asian both developed and emerging economies. Those particular countries have been selected in order to study volatility spillovers, stock market movement patterns, interdependence, financial integration correlations among selected stock markets, and leptokurtosis. Moreover, this research paper provides additional empirical evidence regarding capital markets behaviour (both emerging and developed), volatility spillover patterns, similar reaction to external shocks, international contagion, impact of new information on the capital market, investor risk aversion behaviour, risk management optimal strategies and international portfolio diversification benefits. Increasing volatility spill over impacts makes it more difficult to diversify away the portfolio risk. The portfolio selection strategies of international investors are very important, especially in the context of globalization and financial liberalization. Thus, superior investment performance can be achieved on the basis of international portfolio diversification. A diversified investment portfolio can generate significant returns and minimize risk exposure.

GARCH $(1,1)$ model is a combination of ARCH (1) and GARCH (1) term which is denoted by $\mathrm{a} 1+\mathrm{b} 1$ which shows positively results for empirical studies. Symmetric and asymmetric GARCH models revealed that all selected financial markets are highly volatile, including the presence of leverage effect. In particular, BUX index (Hungary), DIJA index (USA), DAX index (Germany), BSE index (India) and S\&P TSX index (Canada) were found with high positive volatility after global financial crisis. The stock market of IBEX35 index (Spain), WIG20 index (Poland) and SSE index (China) were found with multiple presence of transmitting pattern that creates mixture of negative and positive volatility at same time and makes slower the actual asset growth. NIKKEI 225 index (Japan), FTSE100 index (UK), BET index (Romania), and CAC40 index (France) faced larger amount of corrections in asset prices and may possibly nominated for probable markets which may grow upward in straight directions. It is noted that Dow Jones Industrial Average is replaced by S\&P TSX of Canada in following developing market pattern. Countries like India, China, Hungary, Romania, France, Poland and Spain follow transmitting pattern more of Canada compared to DIJA of USA. There are only several exceptional cases of developed financial markets, i.e. Japan, Germany and UK, represented by their main stock indices, i.e. NIKKEI 225, DAX and FTSE 100 that follow more the movement of USA stock market represented by Dow Jones Industrial Average (DJIA) index compared to S\&P TSX index of Canada. 
In general, it is being observed in most financial market research studies that emerging stock markets follow the movement pattern of certain developed stock markets. For instance, Dow Jones or S\&P 100 stock indices are very important. GARCH family models can map volatility magnitudes and asymmetric models can capture asymmetric events such as leverage effect of volatility clusters. Contagion impact also indicates mapping of volatility clusters of specific stock market with application of asymmetric GARCH type models. We employed EGARCH and GJR models in order to estimate asymmetry for our cluster of stock markets. In the process of employed asymmetric models we objected to abstract leverage effect or volatility clusters in respective financial markets. With availability of research outcome and based on employed statistics we provide capture of relationship between selected financial market. The empirical findings of our research study provide significant information in order to highlight the dependence between certain international stock markets. Further we have crossed examined cross-correlations in case if exists. In addition to construct risk-leverage portfolio, such information provides essential input to determine dependency over related financial markets. As diversified portfolios are results of splitting up total investments that determine and distribute total risks.

A further extension of this research paper will focus on investigating co-movements and inter-linkage between developed and emerging capital markets in Asia, Africa, Europe, South America and North America based on international portfolio diversification. Further research could also cover a much longer period of time, so that we can analyze the implications of several extreme financial events. Our research study contributes to existing literature because the empirical evidence has a great impact on international investment process and risk management, especially in terms of globalization and financial liberalization. International diversification contributes to ensuring the protection of portfolio value by reducing overall investment risk and returns volatility. Our empirical findings should be useful to regulators, domestic and foreign financial market practitioners, policy makers, corporations, institutional and private investors, researchers, academics and scientists. For instance, regulators and policy makers can use this research study to implement a legal regulatory framework in order to temper cross-market correlations of excessive stock price movements. Institutional and private investors can use our empirical study for a better understanding of optimal portfolio construction, capital asset pricing and risk management. Moreover, our original selection of certain developed and emerging stock markets from three different continents can provide a useful perspective for researchers, academics and scientists. However, our empirical study has certain limitations regarding the relatively small number of selected stock markets, i.e. only 12 stock markets (7 developed and 5 emerging stock markets). More than that, the econometric framework can be more elaborated by applying methods based on artificial intelligence, fuzzy logic, data mining or hybrid methods. Future research directions will take these aspects into account in order to improve the empirical results.

\section{References}

Ahmed, A. E. M., \& Suliman, S. Z. (2011). Modeling stock market volatility using GARCH models evidence from Sudan. International Journal of Business and Social Science, 2(23 Special Issue), 114-128. 
Ahmed, R., Vveinhardt, J., Štreimikienè, D., Ghauri, S., \& Ashraf, M. (2018). Stock returns, volatility and mean reversion in emerging and developed financial markets. Technological and Economic Development of Economy, 24(3), 1149-1177. https://doi.org/10.3846/20294913.2017.1323317

Aktan, B., Korsakienè, R., \& Smaliukiene, R. (2010). Time-varying volatility modelling of Baltic stock Markets. Journal of Business Economics and Management, 11(3), 511-532. https://doi.org/10.3846/jbem.2010.25

Alberg, D., Shalit, H., \& Yosef, R. (2008). Estimating stock market volatility using asymmetric GARCH models. Applied Financial Economics, 18(5), 1201-1208. https://doi.org/10.1080/09603100701604225

Baele, L. (2003). Volatility spillover effects in European equity markets (CentER Discussion Paper; Vol. 2003-114). SSRN. https://doi.org/10.2139/ssrn.302851

Bahadur, G. C. S., Kothari, R., \& Thagurathi, R. (2017). Volatility spillover effect in Indian stock market. Janapriya Journal of Interdisciplinary Studies, 5, 83-101. https://doi.org/10.3126/jiis.v5i0.17842

Bala, D. A., \& Takimoto, T. (2017). Stock markets volatility spillovers during financial crises: A DCCMGARCH with skewed-t density approach. Borsa Istanbul Review, 17(1), 25-48. https://doi.org/10.1016/j.bir.2017.02.002

Basso, A., \& Ferretti, P. (1994). Stock returns: An analysis of the Italian market with GARCH models. In Operations research models in quantitative finance. Contributions to management science (pp. 187-209). Physica-Verlag HD. https://doi.org/10.1007/978-3-642-46957-2_10

Baur, D. G. (2003). Testing for contagion - mean and volatility contagion. Journal of Multinational Financial Management, 13(4-5), 405-422. https://doi.org/10.1016/S1042-444X(03)00018-5

Będowska-Sójka, B., \& Echaust, K. (2019). Commonality in liquidity indices: The emerging European stock markets. Systems, 7(2), 24. https://doi.org/10.3390/systems7020024

Beirne, J., Caporale, G. M., Schulze-Ghattas, M., \& Spagnolo, N. (2013). Volatility spillovers and contagion from mature to emerging stock markets. Review of International Economics, 21(5), 1060-1075. https://doi.org/10.1111/roie.12091

Bekaert, G, Harvey, C. R., \& Ng, A. (2005). Market integration and contagion. Journal of Business, 78(1), 39-69. https://doi.org/10.1086/426519

Bhar, R., \& Nikolova, B. (2007). Analysis of mean and volatility spillovers using BRIC countries, regional and world equity index returns. Journal of Economic Integration, 22(2), 369-381. https://doi.org/10.11130/jei.2007.22.2.369

Bollerslev, T. (1986). Generalized autoregressive conditional heteroscedasticity. Journal Economic, 31(3), 307-327. https://doi.org/10.1016/0304-4076(86)90063-1

Bonfiglioli, A., \& Favero, C. A. (2005). Explaining co-movements between stock markets: The case of US and Germany. Journal of International Money and Finance, 24(8), 1299-1316. https://doi.org/10.1016/j.jimonfin.2005.08.016

Bonga-Bonga, L. (2018). Uncovering equity market contagion among BRICS countries: An application of the multivariate GARCH model. The Quarterly Review of Economics and Finance, 67, 36-44. https://doi.org/10.1016/j.qref.2017.04.009

Bonilla, C. A., \& Sepúlveda, J. (2011). Stock returns in emerging markets and the use of GARCH models. Applied Economics Letters, 18(14), 1321-1325. https://doi.org/10.1080/13504851.2010.537615

Calvo, S., \& Reinhart, C. (1996). Capital flows to Latin America: Is there evidence of contagion effects? In G. A. Calvo, M. Goldstein, \& E. Hochreiter (Eds.), Private capital flows to emerging markets after the Mexican Crisis (pp. 151-171). Peterson Institute for International Economics, Washington, DC.

Chan, W. H., \& Feng, L. (2008). Extreme news events, long-memory volatility and time varying risk premia in stock market returns. SSRN. https://doi.org/10.2139/ssrn.1183173

Chang, C. L., \& McAleer, M. (2017). The correct regulatory condition and interpretation of asymmetry in EGARCH. Economics Letters, 161(C), 52-55. https://doi.org/10.1016/j.econlet.2017.09.017 
Chiang, T. C., Bang, N. J., \& Huimin, L. (2007). Dynamic correlation analysis of financial contagion: Evidence from Asian markets. Journal of International Money Finance, 26(7), 1206-1228. https://doi.org/10.1016/j.jimonfin.2007.06.005

Chitkasame, T., \& Tansuchat, R. (2019). An analysis of contagion effect on ASEAN stock market using multivariate Markov switching DCC GARCH. Thai Journal of Mathematics (Special Issue: Structural Change Modeling and Optimization in Econometrics), 135-152.

Choudhry, T. (1996). Stock market volatility and the crash of 1987: Evidence from six emerging markets. Journal of International Money and Finance, 15(6), 969-981. https://doi.org/10.1016/S0261-5606(96)00036-8

Chowdhury, A. H., \& Arefin, M. K. (2017). Modelling co-movement of different sectors in Dhaka Stock Exchange (DSE) using asymmetric BVAR-GARCH models. Journal of Finance and Economics, 5(3), 105-117. https://doi.org/10.12691/jfe-5-3-3

Chua, C. L., \& Tsiaplias, S. (2019). Information flows and stock market volatility. Journal of Applied Econometrics, 34(1), 129-148. https://doi.org/10.1002/jae.2649

Dedi, L., Yavas, B. F., \& McMillan, D. (2016). Return and volatility spillovers in equity markets: An investigation using various GARCH methodologies. Cogent Economics \& Finance, 4(1), 1266788. https://doi.org/10.1080/23322039.2016.1266788

Domowitz, I., Glen, J., \& Madhavan, A. (1998). International cross-listing and order ‡ow migration: Evidence from an emerging market. Journal of Finance, 53(6), 2001-2027. https://doi.org/10.1111/0022-1082.00081

Dornbusch, R., Park, Y. C., \& Claessens, S. (2000). Contagion: Understanding how it spreads. The World Bank Research Observer, 15(2), 177-197. https://doi.org/10.1093/wbro/15.2.177

Dutta, P., Noor, M. H., \& Dutta, A. (2017). Impact of oil volatility shocks on global emerging market stock returns. International Journal of Managerial Finance, 13(5), 578-591. https://doi.org/10.1108/IJMF-03-2017-0039

Dutta, A. (2014). Modelling volatility: Symmetric or asymmetric GARCH models? Journal of Statistics: Advances in Theory and Applications, 12(2), 99-108.

Engle, R., Ito, T., \& Lin, W. (1990). Meteor showers or heat waves? Heteroskedastic intra-daily volatility in the foreign exchange market. Econometrica, 58(3), 525-542. https://doi.org/10.2307/2938189

Engle, R. F. (2001). GARCH 101: The use of ARCH/GARCH models in applied econometrics. Journal of Economic Perspectives, 15(4), 157-168. https://doi.org/10.1257/jep.15.4.157

Fasanya, I. O., \& Akinde, M. A. (2019). Volatility transmission in the Nigerian financial market. The Journal of Finance and Data Science, 5(2), 99-115. https://doi.org/10.1016/j.jfds.2019.01.003

Fleming, J., Kirby, C., \& Ostdiek, B. (1998). Information and volatility linkages in the stock, bond, and money markets. Journal of Financial Economics, 49(1), 111-137. https://doi.org/10.1016/S0304-405X(98)00019-1

Forbes, K. J., \& Rigobon, R. (2002). No contagion, only interdependence: Measuring stock market comovements. Journal of Finance, 57(5), 2223-2261. https://doi.org/10.1111/0022-1082.00494

Giovannetti, G., \& Velucchi, M. (2013). A spillover analysis of shocks from US, UK and China on African financial markets. Review of Development Finance, 3(4), 169-179. https://doi.org/10.1016/j.rdf.2013.10.002

Girard, E., \& Biswas, R. (2007). Trading volume and market volatility: Developed versus emerging stock markets. The Financial Review, 42(3), 429-459. https://doi.org/10.1111/j.1540-6288.2007.00178.x

Glosten, L. R., Jagannathan, R., \& Runkle, D. E. (1993). On the relation between the expected value and the volatility of the nominal excess return on stocks. Journal of Finance, 48(5), 1779-1801. https://doi.org/10.1111/j.1540-6261.1993.tb05128.x 
Gokcan, S. (2000). Forecasting volatility of emerging stock markets: Linear versus non-linear GARCH models. Journal of Forecasting, 19(6), 499-504. https://doi.org/10.1002/1099-131X(200011)19:6<499::AID-FOR745>3.0.CO;2-P

Hamao, Y., Masulis, R., \& Ng, V. (1990). Correlations in price changes and volatility across international stock markets. The Review of Financial Studies, 3(2), 281-307. https://doi.org/10.1093/rfs/3.2.281

Hassan, S. A. (2017). A time series analysis of major indexes using GARCH model with regime shifts. International Journal of Financial Research, 8(4), 127-133. https://doi.org/10.5430/ijfr.v8n4p127

Herrera, F. L., Salgado, R. J. S, \& Ake, S. C. (2015). Volatility dependence structure between the Mexican Stock Exchange and the World Capital Market. Investigación Económica, 74(293), 69-97. https://doi.org/10.1016/j.inveco.2015.06.001

Hol, E. M. J. H. (2003). The stochastic volatility in mean model: Empirical evidence from international stock markets. In Dynamic Modeling and Econometrics in Economics and Finance: Vol. 6. Empirical Studies on Volatility in International Stock Markets. (pp. 24-57). Springer. https://doi.org/10.1007/978-1-4757-5129-1

Hung, N. T. (2019). Return and volatility spillover across equity markets between China and Southeast Asian countries. Journal of Economics, Finance and Administrative Science, 24(47), 66-81. https://doi.org/10.1108/JEFAS-10-2018-0106

Jain, P., \& Sehgal, S. (2019). An examination of return and volatility spillovers between mature equity markets. Journal of Economics and Finance, 43(1), 180-210. https://doi.org/10.1007/s12197-018-9442-1

Jebran, K., Chen, S., Ullah, I., \& Mirza, S. S. (2017). Does volatility spillover among stock markets varies from normal to turbulent periods? Evidence from emerging markets of Asia. The Journal of Finance and Data Science, 3(1-4), 20-30. https://doi.org/10.1016/j.jfds.2017.06.001

Kenourgios, D. (2014). On financial contagion and implied market volatility. International Review of Financial Analysis, 34, 21-30. https://doi.org/10.1016/j.irfa.2014.05.001

Kumar, S., Moon Haque, M., \& Sharma, P. (2018). Volatility spillovers across major emerging stock markets. Asia-Pacific Journal of Management Research and Innovation, 13(1-2), 13-33. https://doi.org/10.1177/2319510X17740043

Leung, H., Schiereck, D., \& Schroeder, F. (2017). Volatility spillovers and determinants of contagion: Exchange rate and equity markets during crises. Economic Modelling, 61, 169-180. https://doi.org/10.1016/j.econmod.2016.12.011

Li, Y., \& Giles, D. E. (2015). Modelling volatility spillover effects between developed stock markets and Asian emerging stock markets. The International Journal of Finance and Economics, 20(2), 155-177. https://doi.org/10.1002/ijfe.1506

Lin, Z. (2018). Modelling and forecasting the stock market volatility of SSE Composite Index using GARCH models. Future Generation Computer Systems Journal, 79(P3), 960-972. https://doi.org/10.1016/j.future.2017.08.033

Liu, H., C., \& Hung, J. C. (2010). Forecasting S\&P - 100 stock index volatility: The role of volatility asymmetry and distributional assumption in GARCH models. Expert Systems with Applications, 37(7), 4928-4934. https://doi.org/10.1016/j.eswa.2009.12.022

Majdoub, J., \& Sassi, S. B. (2017). Volatility spillover and hedging effectiveness among China and emerging Asian Islamic equity indexes. Emerging Markets Review, 31, 16-31. https://doi.org/10.1016/j.ememar.2016.12.003

Mathur, S., Chotia, V., \& Rao, N. V. M. (2016). Modelling the impact of Global Financial Crisis on the Indian stock market through GARCH models. Asia-Pacific Journal of Management Research and Innovation, 12(1), 11-22. https://doi.org/10.1177/2319510X16650056

McAleer, M., Hoti, S., \& Chan, F. (2009). Structure and asymptotic theory for multivariate asymmetric conditional volatility. Econometric Reviews, 28(5), 422-440. https://doi.org/10.1080/07474930802467217 
Miralles-Marcelo, J. L., Miralles-Quirós, J. L., \& del Mar Miralles-Quirós, M. (2013). Multivariate GARCH models and risk minimizing portfolios: The importance of medium and small firms. The Spanish Review of Financial Economics, 11(1), 29-38. https://doi.org/10.1016/j.srfe.2013.03.001

Morales-Zumaquero, A., \& Sosvilla-Rivero, S. (2016). Volatility spillovers between foreign-exchange and stock markets (Bath Economics Research Papers, No. 58/17). SSRN. https://doi.org/10.2139/ssrn.2897481

Nelson, D. B. (1991). Conditional heteroskedasticity in asset returns: A new approach. Econometrica, 59(2), 347-370. https://doi.org/10.2307/2938260

Patel, S., \& Sarkar, A. (1998). Crises in developed and emerging stock markets. Financial Analysts Journal, 54(6), 50-61. https://doi.org/10.2469/faj.v54.n6.2225

Quoreshi, A. M. M. S., Uddin, R., \& Jienwatcharamongkhol, V. (2019). Equity market contagion in return volatility during Euro Zone and Global Financial Crises: Evidence from FIMACH model. Journal of Risk and Financial Management, 12(2), 94. https://doi.org/10.3390/jrfm12020094

Raczko, M. A. (2015). Volatility contagion: New evidence from market pricing of volatility risk (Bank of England Working Paper No. 552). SSRN. https://doi.org/10.2139/ssrn.2667682

Rao, R., Kanagaraj, S. V. A., \& Tripathy, N. (2008). Does individual stock futures affect stock market volatility in India? Journal of the Indian Institute of Economics, 50(1), 125-135.

Rejeb, A. B., \& Boughrara, A. (2015). Financial integration in emerging market economies: Effects on volatility transmission and contagion. BorsaIstanbul Review, 15(3), 161-179. https://doi.org/10.1016/j.bir.2015.04.003

Roni, B., Abbas, G., \& Wang, S. (2018). Return and volatility spillovers effects: Study of Asian emerging stock markets. Journal of Systems Science and Information, 6(2), 97-119. https://doi.org/10.21078/JSSI-2018-097-23

Ross, S. A. (1989). Information and volatility: The no-arbitrage martingale approach to timing and resolution irrelevancy. Journal of Finance, 44(1), 1-17. https://doi.org/10.1111/j.1540-6261.1989.tb02401.x

Sentana, E. (2018). Volatility, diversification and contagion (CEPR Discussion Papers 12824). Centro de estudios monetarios y financieros of Madrid, Spain.

Silvia, A., Zulpahmi, \& Sumardi. (2019). Spillovereffect of Islamic stock markets in Asia. European Research Studies Journal, 22(2), 28-40. https://doi.org/10.35808/ersj/1424

Slimane, F. B., Mehanaoui, M., \& Kazi, I. A. (2013). How does the financial crisis affect volatility behavior and transmission among European stock markets? International Journal of Financial Studies, 1(3), 81-101. https://doi.org/10.3390/ijfs1030081

Spulbar, C., \& Birau, R. (2019). Emerging research on monetary policy, banking, and financial markets. IGI Global, USA. https://doi.org/10.4018/978-1-5225-9269-3

Srinivasan, P. (2011). Modeling and forecasting the stock market volatility of S\&P 500 index using GARCH models. The IUP Journal of Behavioral Finance, 8(1), 51-69.

Taly, I. (2015). Study on return and volatility spillover effects among stock, CDS, and foreign exchange markets in Korea. Journal of East Asian Economic Integration, 19(3), 275-322. https://doi.org/10.11644/KIEP.JEAI.2015.19.3.299

Tao, J., \& Green, C. J. (2012). Asymmetries, causality and correlation between FTSE100 spot and futures: A DCC-TGARCH-M analysis. International Review of Financial Analysis, 24(C), 26-37. https://doi.org/10.1016/j.irfa.2012.07.002

Taufiq, H., Nassir, A.B., \& Shamsher, M. (2006). The heat waves or meteor showers hypothesis: Test on selected Asian emerging and developed stock markets. Investment Management and Financial Innovations, 3(1), 120-131. 
Tran, T. B. N. (2018). Contagion risks in emerging stock markets: New evidence from Asia and Latin America. Journal of Risk and Financial Management, 11(4), 89. https://doi.org/10.3390/jrfm11040089

Valls, N., \& Chuliá, H. (2014).Volatility transmission between the stock and currency markets in emerging Asia: The impact of the global financial crisis. (Working Paper 2014/31 1/26, pp. 1-26). Research Institute of Applied Economics.

Vidanage, T. N., Carmignani, F., \& Singh, T. (2017). Predictability of return volatility across different emerging capital markets: Evidence from Asia. South Asian Journal of Macroeconomics and Public Finance, 6(2), 157-177. https://doi.org/10.1177/2277978717727172

Withanage, Y., \& Jayasinghe, P. (2017). Volatility spillovers between South Asian stock markets: Evidence from Sri Lanka, India and Pakistan. Sri Lanka Journal of Economic Research, 5(1), 79-94. https://doi.org/10.4038/sljer.v5i1.59

$\mathrm{Xu}$, Y., Taylor, N., \& Lu, W. (2018). Illiquidity and volatility spillover effects in equity markets during and after the global financial crisis: An MEM approach (Cardiff Economics Working Papers E2018/6). Cardiff University, Cardiff Business School, Economics Section. https://doi.org/10.1016/j.irfa.2018.01.011

Yu, Y., Wang, Y., \& Yi, R. (2019). Risk transmission beyond financial crises: Volatility spillovers and spillbacks between SMICs and the U.S. SSRN. https://doi.org/10.2139/ssrn.3446629 